\title{
Universiteit
}

Leiden

The Netherlands

\section{Synthesis of pseudo-disaccharide analogues of lipid A: haptens for the generation of antibodies with glycosidase activity towards lipid A}

Berg, R.J.B.H.N. van den; Noort, D.; Marel, G.A. van der; Boom, J.H. van; Benschop, H.P.

\section{Citation}

Berg, R. J. B. H. N. van den, Noort, D., Marel, G. A. van der, Boom, J. H. van, \& Benschop, H. P. (2002). Synthesis of pseudo-disaccharide analogues of lipid A: haptens for the generation of antibodies with glycosidase activity towards lipid A. Journal Of Carbohydrate Chemistry, 21(3), 167-188. doi:10.1081/CAR-120004331

Version:

Publisher's Version

License:

Licensed under Article 25fa Copyright Act/Law (Amendment Taverne)

Downloaded from: https://hdl.handle.net/1887/3151641

Note: To cite this publication please use the final published version (if applicable). 


\section{SYNTHESIS OF PSEUDO-DISACCHARIDE ANALOGUES OF LIPID A: HAPTENS FOR THE GENERATION OF ANTIBODIES WITH GLYCOSIDASE ACTIVITY TOWARDS LIPID A}

Richard J.B.H.N. van den Berg, Daan Noort, Gijs A. van der Marel , Jacques H. van Boom \& Hendrik P. Benschop

To cite this article: Richard J.B.H.N. van den Berg , Daan Noort, Gijs A. van der Marel, Jacques H. van Boom \& Hendrik P. Benschop (2002) SYNTHESIS OF PSEUDO-DISACCHARIDE ANALOGUES OF LIPID A: HAPTENS FOR THE GENERATION OF ANTIBODIES WITH GLYCOSIDASE ACTIVITY TOWARDS LIPID A, Journal of Carbohydrate Chemistry, 21:3, 167-188, DOI: 10.1081/CAR-120004331

To link to this article: https://doi.org/10.1081/CAR-120004331

Published online: 20 Aug 2006.

Submit your article to this journal $₫$

Џ Article views: 114

Q View related articles ¿ 


\title{
SYNTHESIS OF PSEUDO-DISACCHARIDE ANALOGUES OF LIPID A: HAPTENS FOR THE GENERATION OF ANTIBODIES WITH GLYCOSIDASE ACTIVITY TOWARDS LIPID A
}

\author{
Richard J. B. H. N. van den Berg, ${ }^{1}$ Daan Noort, ${ }^{1}$ \\ Gijs A. van der Marel, ${ }^{2}$ Jacques H. van Boom, ${ }^{2, *}$ \\ and Hendrik P. Benschop ${ }^{1}$ \\ ${ }^{1}$ Department of Chemical Toxicology, TNO Prins Maurits Laboratory, \\ P.O. Box 45, NL-2280 AA Rijswijk, The Netherlands \\ ${ }^{2}$ Leiden Institute of Chemistry, Gorlaeus Laboratories, University of \\ Leiden, P.O. Box 9502, NL-2300 RA Leiden, The Netherlands
}

\begin{abstract}
In order to develop a generic treatment of sepsis caused by infections with Gram-negative bacteria, a series of pseudo-disaccharide analogues of lipid A (1-5) was synthesized. These adducts not only harbor a 2acylaminodideoxynojirimycin unit mimicking the transition state of the glycosidic hydrolysis, but also a 2-N, 3-O-diacylated glucosamine moiety capable of generating catalytic antibodies with more selective glycosidase properties towards lipid A.
\end{abstract}

\section{INTRODUCTION}

Endotoxins, the complex lipopolysaccharides (LPS) situated in the outer membrane of Gram-negative bacteria, are extremely potent toxins. ${ }^{[1]}$ Most of the biological activities of LPS reside in the small terminal disaccharide phospholipid moiety known

\footnotetext{
*Corresponding author. E-mail: j.boom@chem.leidenuniv.nl
} 
as lipid A. ${ }^{[2]}$ Therapeutic strategies under development aim at either preventing endotoxin interaction with host effector cells or interrupting endotoxin mediated signal transduction pathways. This objective can be attained in blocking the synthesis and binding of endotoxin, thus neutralizing its activity. ${ }^{[3-5]}$

Our approach to suppress sepsis caused by Gram-negative bacteria is based on catalytic antibodies capable of degrading lipid A via hydrolysis of the interglycosidic bond resulting in the formation of non-toxic monosaccharides. Since catalytic antibodies are supposed to have catalytic activities with tailor-made specificities, these abzymes have many potential therapeutically applications. For example, Landry et al. succeeded in the generation of a catalytic antibody that was effective in detoxifying cocaine from the blood stream via hydrolysis of the benzoyl ester function. ${ }^{[6-9]}$ Based on this result it was envisioned that a generic treatment of sepsis caused by Gramnegative bacteria might be feasible using specific and selective glycosidase antibodies capable of degrading lipid A.

Several groups have reported the design and generation of antibodies with glycosidase activity. ${ }^{[10-16]}$ In general, haptens are based on iminocyclitol glycosidase inhibitors such as deoxynojirimycin and isofagomine, which in terms of polarity and shape resemble the transition state of the glycosidic cleavage reaction. The protonated endocyclic nitrogen atom of iminocyclitols mimics the electronic charge developing in the transition state formed during cleavage of the interglycosidic bond. In a previous paper ${ }^{[17]}$ we reported the preparation of 2-acylaminodideoxynojirimycin derivatives mimicking the transition state of the hydrolysis of the interglycosidic bond at the nonreducing end of lipid A. It turned out that monoclonal antibodies raised against these haptens showed promising glycosidase activity (results to be published).

It was envisaged, based on the early studies by Dong ${ }^{[18]}$ as well as $\mathrm{Yu}^{[14]}$ that conjugation of 2- $\mathrm{N}, 3$-O-diacylated glucosamine derivatives to 2-acylaminodideoxynojirimycin units would afford haptens suitable to raise specific glycosidase antibodies towards lipid A. The latter can be achieved by anchoring the 2-N, 3-O-diacylated glucosamine units, which mimic the reducing part of lipid A, to the endocyclic nitrogen atom of the iminoglucitol moieties via a flexible linker.

We here report the synthesis of several pseudo-disaccharide analogues of lipid A (i.e. compounds 1-5, Figure 1) containing 2-acylaminodideoxynojirimycins as well as 2-N, 3-O-diacylated glucosamine units.

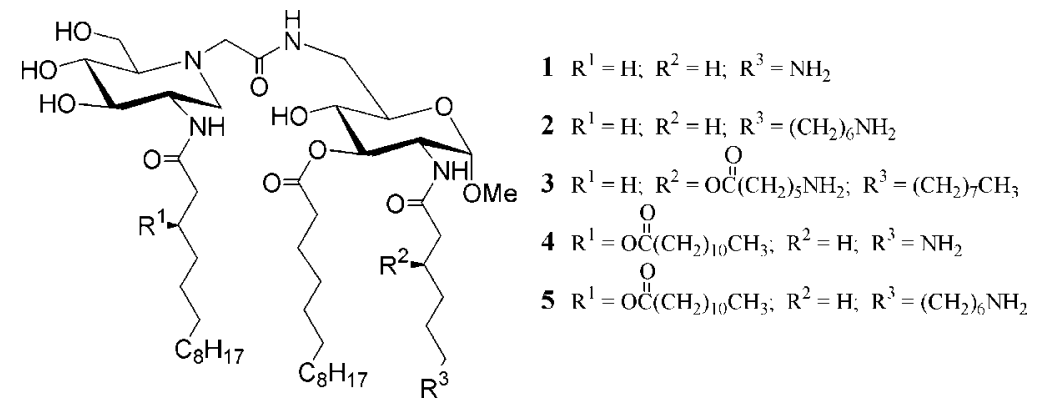

Figure 1. 


\section{RESULTS AND DISCUSSION}

The easily accessible 3,4,6-tri- $O$-benzyl-2- $N$-benzyloxycarbonylamino-1,2,5-trideoxy-1,5-iminoglucitol (6) ${ }^{[17]}$ was used as a starting compound for the preparation of iminocyclitols 11 and 12 (Scheme 1) mimicking the non-reducing part of lipid A. In the first step, the carboxymethyl linker in 7 was introduced by alkylation of the endocyclic nitrogen atom of $\mathbf{6}$ with tert-butyl bromoacetate under the agency of cesium carbonate in dimethyl formamide ${ }^{[19]}$ to give compound 7 in a yield of $95 \%$. Selective removal of the benzyloxycarbonyl (Z) protecting group in 7 proceeded smoothly by hydrogenation over Degussa type palladium on carbon to give $\mathbf{8}$ in a quantitative yield. PyBOP mediated coupling ${ }^{[20]}$ of amine 8 with myristic acid and (R)-3-dodecanoyloxytetradecanoic acid ${ }^{[21]}$ gave the $N$-acylated derivatives $\mathbf{9}$ and 10, respectively, in good yield. Removal of the tert-butyl group in compounds $\mathbf{9}$ and $\mathbf{1 0}$ was readily effected by treatment with neat trifluoroacetic acid, affording building blocks $\mathbf{1 1}$ and $\mathbf{1 2}$ in $100 \%$ and $83 \%$ yield, respectively.

The individual hapten units $\mathbf{3 4}, \mathbf{3 5}$ and $\mathbf{3 6}$, mimicking the reducing part of lipid A, were obtained by subjecting D-glucosamine (13) to the sequence of reactions depicted in Scheme 2. Accordingly, D-glucosamine (13) was converted in two steps into $N$ benzyloxycarbonyl protected glucosamine 15. ${ }^{[2]}$ Acetonation of 15 with 2,2-dimethoxypropane and a catalytic amount of $p$-toluenesulfonic acid gave partially protected derivative $\mathbf{1 6}$ in a quantitative yield. Condensation of the secondary hydroxyl group in 16 with myristic acid under the agency of $\mathrm{DCC}^{[23]}$ afforded $\mathbf{1 7}$ in a yield of $86 \%$. Removal of the Z-protecting group in $\mathbf{1 7}$ by hydrogenation over palladium on carbon in ethyl acetate gave amine 18 in a quantitative yield. PyBOP mediated condensation of amine 18 with the individual acids 19-21, of which the primary amine function was protected with the Z-group, afforded the corresponding derivatives 22-24. At this stage, $N$-acylated compound $\mathbf{2 2}$ was transformed into the primary amino derivative $\mathbf{3 4}$ by following the four-step process as portrayed in Scheme 2. Thus, de-acetonation of compound 22 with trifluoroacetic acid in aqueous tetrahydrofuran, ${ }^{[24]}$ followed by
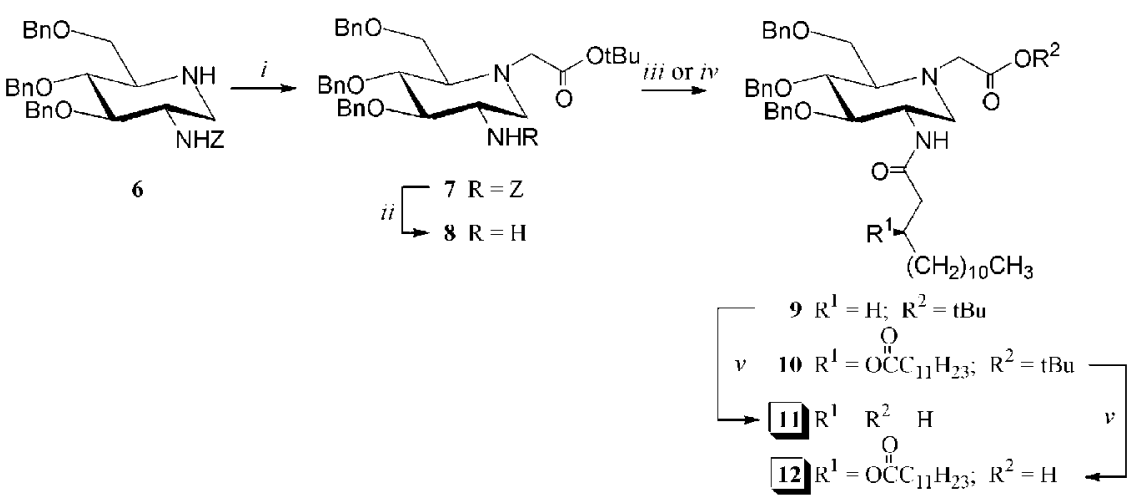

Scheme 1. Conditions: (i) tert-butyl bromoacetate, $\mathrm{Cs}_{2} \mathrm{CO}_{3}, \mathrm{DMF}, 95 \%$; (ii) EtOAc, 5\% $\mathrm{Pd} / \mathrm{C}$, $\mathrm{H}_{2}, 100 \%$; (iii) myristic acid, PyBOP, DiPEA, DCM, 89\%; (iv) (R)-3-HOOCCH $\mathrm{CHO}_{2}$ $\left(\mathrm{COC}_{11} \mathrm{H}_{23}\right) \mathrm{C}_{11} \mathrm{H}_{23}$, PyBOP, DiPEA, DCM, 70\%; (v) TFA (11, 100\%), (12, 83\%). 

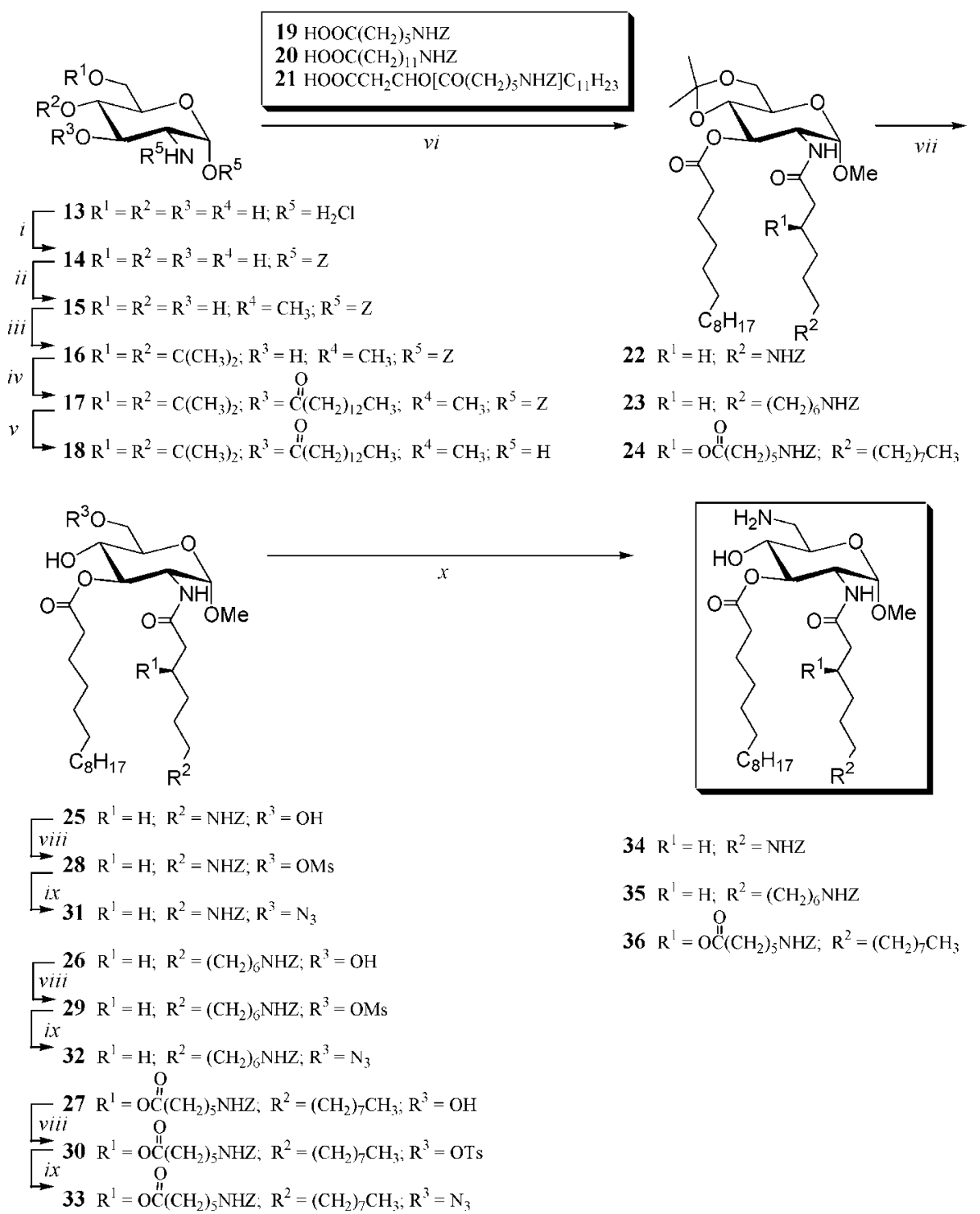

$34 \mathrm{R}^{1}=\mathrm{H} ; \mathrm{R}^{2}=\mathrm{NHZ}$

$35 \mathrm{R}^{1}=\mathrm{H} ; \mathrm{R}^{2}=\left(\mathrm{CH}_{2}\right)_{6} \mathrm{NHZ}$

$36 R^{1}=\stackrel{O}{O}\left(\mathrm{CH}_{2}\right)_{5} \mathrm{NHZ} ; \mathbf{R}^{2}=\left(\mathrm{CH}_{2}\right)_{7} \mathrm{CH}_{3}$

Scheme 2. Conditions: (i) benzyl chloroformate, $\mathrm{NaHCO}_{3}, \mathrm{H}_{2} \mathrm{O}$; (ii) $\mathrm{HCl} / \mathrm{MeOH}(2 \%$, w/w), 53\%; (iii) 2,2-dimethoxypropane, toluene-4-sulfonic acid, acetone, DCM, 100\%; (iv) myristic acid, DCC, DMAP, DCM, 86\%; (v) 5\% Pd/C, $\mathrm{H}_{2}, 100 \%$; (vi) 19/20/21, PyBOP, DiPEA, DCM, (22, 87\%), (23, 96\%), (24, 87\%); (vii) TFA, THF/ $\mathrm{H}_{2} \mathrm{O},(4 / 1, \mathrm{v} / \mathrm{v}),(\mathbf{2 5}, 99 \%),(\mathbf{2 6}, 63 \%),(\mathbf{2 7}$, 87\%); (viii) $\mathrm{MsCl}$ ( $\mathrm{TsCl})$, pyridine, (28, 80\%), (29, 78\%), (30, 79\%); (ix) $\mathrm{NaN}_{3}, \mathrm{DMF}, 80^{\circ} \mathrm{C},(\mathbf{3 1}$, $84 \%),(32,72 \%),(33,73 \%)(x)$ triphenylphosphine (1.5 equiv), $\mathrm{H}_{2} \mathrm{O}$ (1.2 equiv), THF, (34, $100 \%),(35,78 \%),(36,52 \%)$. 
regio-selective sulfonylation of the primary hydroxyl group of diol $\mathbf{2 5}$ gave sulfonylate 28 in an overall yield of $80 \%$. Treatment of the latter derivative with sodium azide in dimethyl formamide at elevated temperature afforded the 6-azidoglucosamine compound 31. Subsequent reduction of the resulting azido function in $\mathbf{3 1}$ under the agency of triphenylphosphine in aqueous tetrahydrofuran ${ }^{[25]}$ gave the requisite 6-amino derivative $\mathbf{3 4}$ in yield of $84 \%$ based on sulfonylate $\mathbf{2 8}$. In a similar way compounds $\mathbf{3 5}$ and $\mathbf{3 6}$ were attained by subjecting acetonides $\mathbf{2 3}$ and $\mathbf{2 4}$ to the same four-step process as described for the synthesis of $\mathbf{3 4}$.

Having the requisite building blocks 11, 12, 34-36 at hand, introduction of the required amide bond of the fully protected compounds $37-\mathbf{4 1}$ could be readily accomplished (see Scheme 3) using PyBOP as the condensation agent. For example, PyBOPmediated condensation of acid $\mathbf{1 1}$ and amine $\mathbf{3 4}$ proceeded smoothly to afford the fully protected hapten $\mathbf{3 7}$ in a yield of $96 \%$. The identity and homogeneity of compound $\mathbf{3 7}$

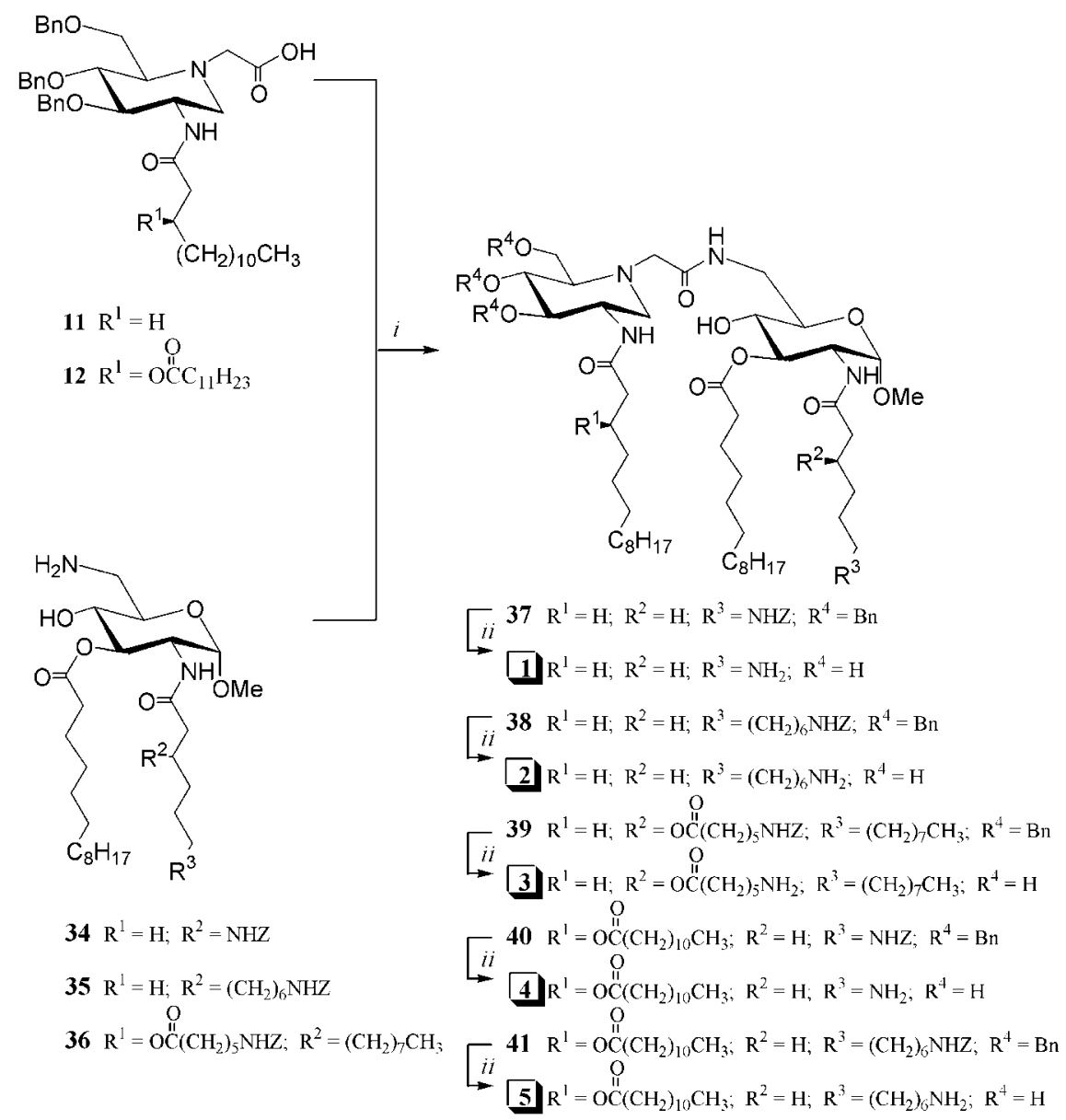

Scheme 3. Conditions: (i) PyBOP, DiPEA, DCM, (37, 96\%), (38, 96\%), (39, 51\%), (40, 88\%), (41, 96\%); (ii) 10\% Pd/C, DMF (1, 100\%), (2, 72\%), (3, 54\%), (4, 88\%), (5, 65\%). 
was fully ascertained by NMR spectroscopy and mass spectrometry. Similar yields were obtained by condensation of $\mathbf{1 1}$ with $\mathbf{3 5}$ and $\mathbf{1 2}$ with $\mathbf{3 4}$ as well as $\mathbf{3 5}$ to yield the fully protected haptens $\mathbf{3 8}, \mathbf{4 0}$ and $\mathbf{4 1}$, respectively. In contrast, the coupling of acid $\mathbf{1 1}$ with amine $\mathbf{3 6}$ to give amide $\mathbf{3 9}$ was in terms of yield not fully satisfactory, and may be ascribed to the increased lipophilicity of amine 36. ${ }^{1} \mathrm{H},{ }^{13} \mathrm{C}$ NMR and mass spectrometric data of the four conjugates 38-41 were in complete accordance with the proposed structures. In the final stage, haptens 37-41 were deprotected by hydrogenolysis over palladium on carbon in dimethyl formamide. Hydrogenolysis of compound $\mathbf{3 7}$ proceeded in near quantitative yield to give hapten 1, the identity and homogeneity of which was fully ascertained by NMR spectroscopy and mass spectrometry. The same results were obtained by hydrogenolysis of compounds $\mathbf{3 8}$ and $\mathbf{4 0}$ to yield the haptens 2 and 4, respectively. Unfortunately, unmasking of compounds 39 and 41 was rather sluggish and led to the isolation of haptens $\mathbf{3}$ and $\mathbf{5}$ in moderate yields. The disappointing outcome of the latter hydrogenolysis may also be due to the intrinsically high lipophilic nature of compounds 39 and $\mathbf{4 1}$. The identity of compounds $\mathbf{2 - 5}$ could be readily ascertained by mass spectrometry. Unfortunately, it turned out that the structure assignment of haptens $\mathbf{2 - 5}$ was seriously hampered by the fact that NMR spectra ${ }^{[26]}$ could not be interpreted due to extensive line broadening.

\section{CONCLUSION}

In summary, we have synthesized five pseudo-lipid A analogues as potential haptens for the generation of catalytic antibodies with glycosidase activity towards lipid A. These haptens contain a primary amino function in the $\mathrm{N}$-acyl chain of the 2- $\mathrm{N}, 3-\mathrm{O}-$ diacylated glucosamine units which will serve as a handle of anchoring haptens $\mathbf{1}-\mathbf{5}$ to a carboxylic acid terminus of a carrier protein. The immunochemical evaluation of the haptens will be reported in due course.

\section{EXPERIMENTAL}

General Methods. Toluene (Merck) was distilled from $\mathrm{P}_{2} \mathrm{O}_{5}$ and stored over sodium wire. Dichloromethane and $N, N$-dimethylformamide were purchased from Biosolve Ltd. and freshly distilled from $\mathrm{CaH}_{2} . \mathrm{N}, \mathrm{N}$-Diisopropylethylamine (Acros Chimica) was distilled from $p$-toluenesulfonyl chloride $(60 \mathrm{~g} / \mathrm{L})$ and redistilled from potassium hydroxide pellets $(40 \mathrm{~g} / \mathrm{L})$. Benzyl chloroformate, tert-butyl bromoacetate, cesium carbonate, $N, N$-dicyclohexylcarbodiimide, 4-(dimethylamino)pyridine, 2,2-dimethoxypropane, D-glucosamine hydrochloride, methanesulfonyl chloride, palladium on carbon (5\%, Degussa E101 NO/W), sodium azide, tetrahydrofuran, toluene- $p$-sulfonic acid, toluene- $p$-sulfonyl chloride and triphenylphosphine were purchased form Fluka. PyBOP was purchased from NovaBiochem. Trifluoroacetic acid was purchased from Acros Chimica. ${ }^{1} \mathrm{H}$ NMR and ${ }^{13} \mathrm{C}$ NMR data were recorded with a Varian VXR-400S (399.9/ $100.6 \mathrm{MHz}) .{ }^{1} \mathrm{H}$ and ${ }^{13} \mathrm{C}$ chemical shifts are given in ppm $(\delta)$ relative to tetramethylsilane $(\delta=0.00)$, DMSO- $\mathrm{d}_{5}(\delta=2.525)$, DMSO-d $\mathrm{d}_{6}(\delta=39.6)$ and $\mathrm{CDCl}_{3}(\delta=77.00)$ as internal standard. The purity of the compounds was established by ${ }^{1} \mathrm{H}$ NMR spectroscopy: $>95 \%$ in all cases. Mass spectra were recorded with a VG Quattro II triple 
quadropole mass spectrometer (Fisons Instruments, Altrincham, UK). Column chromatography was performed on Silica gel 60 (220-440 mesh ASTM, Fluka). TLC analysis was performed with silica gel TLC plates (Fluka) with detection by UV absorption (254 nm) where applicable and charring with $20 \% \mathrm{H}_{2} \mathrm{SO}_{4}$ in $\mathrm{MeOH}$ or ammonium molybdate $(25 \mathrm{~g} / \mathrm{L})$ and ceric ammonium sulfate $(10 \mathrm{~g} / \mathrm{L})$ in $20 \% \mathrm{H}_{2} \mathrm{SO}_{4}$. Prior to reactions that require anhydrous conditions, traces of water were removed by coevaporation with dry toluene. These reactions were conducted under dry argon atmosphere. Hydrogenations were executed at atmospheric pressure under an atmosphere of hydrogen gas maintained by an inflated balloon. Polytetrafluoroethylene (PFTE) filters were purchased from Alltech (Breda, The Netherlands).

3,4,6-Tri- $O$-benzyl-2-[(benzyloxycarbonyl)amino $]-1,5-N-[(O$-tert-butyl-carboxymethyl)imino]-1,2,5-trideoxy-D-glucitol (7). To a solution of 6 (1.20 g, $2.12 \mathrm{mmol})$ in DMF $(20 \mathrm{~mL})$ cesium carbonate $(700 \mathrm{mg}, 2.14 \mathrm{mmol})$ and tert-butyl bromoacetate $(1.15 \mathrm{~mL}, 7.81 \mathrm{mmol})$ were added. The reaction mixture was stirred for $16 \mathrm{~h}$ at ambient temperature, after which TLC analysis indicated complete conversion of starting material into a compound with $R_{\mathrm{f}}=0.92$ (ethyl acetate/hexane, 1:1, v/v). The mixture was diluted with DCM (100 mL) and washed with aqueous $\mathrm{NaOH}(1 \mathrm{M}, 50 \mathrm{~mL})$. After drying over $\mathrm{MgSO}_{4}$, the organic layer was concentrated in vacuo. The crude product was purified by silica gel column chromatography. Elution was performed with DCM/ $\mathrm{MeOH}(100: 0 \rightarrow 96.5: 3.5, \mathrm{v} / \mathrm{v})$. Yield $1.37 \mathrm{~g}(95 \%) .{ }^{1} \mathrm{H}$ NMR $\left(\mathrm{CDCl}_{3}\right): \delta=1.37(\mathrm{~s}, 9 \mathrm{H}$, $\left.\mathrm{CH}_{3}, t \mathrm{Bu}\right), 2.71$ (dd, 1H, H-1ax, $\mathrm{J}_{1 \mathrm{ax}, 1 \mathrm{eq}}=11.6 \mathrm{~Hz}, \mathrm{~J}_{1 \mathrm{ax}, 2}=8.9 \mathrm{~Hz}$ ), 3.04 (br. s, 1H, H-5), 3.10 (br. d, 1H, H-1eq), 3.27 (d, 1H, Ha-acetyl, J=17.7 Hz), 3.35 (br. t, 1H, H-3), 3.52 $\left(\mathrm{dd}, 1 \mathrm{H}, \mathrm{H}-6, \mathrm{~J}_{6,6^{\prime}}=10.5 \mathrm{~Hz}, \mathrm{~J}_{5,6}=2.8 \mathrm{~Hz}\right), 3.57$ (d, 1H, Hb-acetyl, J = 17.7 Hz), 3.59 (t, $1 \mathrm{H}, \mathrm{H}-4), 3.72$ (dd, 1H, H-6', J $\left.\mathrm{J}_{6,6^{\prime}}=10.5 \mathrm{~Hz}, \mathrm{~J}_{5,6^{\prime}}=3.9 \mathrm{~Hz}\right), 3.79$ (m, 1H, H-2), 4.40$4.76\left(\mathrm{~m}, 6 \mathrm{H}, 3 \times \mathrm{CH}_{2} \mathrm{Bn}\right), 4.89(\mathrm{~s}, 1 \mathrm{H}, \mathrm{NH}), 5.05$ (dd, 2H, $\left.\mathrm{CH}_{2} \mathrm{Z}\right), 7.18-7.39(\mathrm{~m}$, $20 \mathrm{H}, \mathrm{CH}$-arom Bn/Z). ${ }^{13} \mathrm{C}\left\{{ }^{1} \mathrm{H}\right\} \mathrm{NMR}\left(\mathrm{CDCl}_{3}\right): \delta=28.16\left(\mathrm{CH}_{3} t \mathrm{Bu}\right), 50.88(\mathrm{C}-2), 53.38$ (C-1), $55.08\left(\mathrm{CH}_{2}\right.$ tert-butyl acetate), 61.61 (C-5), $66.02(\mathrm{C}-6), 66.51\left(\mathrm{CH}_{2} \mathrm{Z}\right), 73.39$, 73.66, $73.97\left(3 \times \mathrm{CH}_{2} \mathrm{Bn}\right), 78.39(\mathrm{C}-4), 80.90(\mathrm{Cq} t \mathrm{Bu}), 81.43(\mathrm{C}-3), 127.58-128.50$ $(\mathrm{CH}$-arom $\mathrm{Bn} / \mathrm{Z}), 156.00(\mathrm{C}=\mathrm{O} \mathrm{Z}), 170.63(\mathrm{C}=\mathrm{O}$ tert-butyl acetyl). ES-MS; $\mathrm{m} / z$ : 681.5, $[\mathrm{M}+\mathrm{H}]^{+}$; monoisotopic MW calculated for $\mathrm{C}_{41} \mathrm{H}_{48} \mathrm{~N}_{2} \mathrm{O}_{7}=680.35$.

2-Amino-3,4,6-tri-O-benzyl-1,5- $\mathrm{N}$-[(O-tert-butyl-carboxymethyl)imino]-1,2,5-trideoxy-D-glucitol (8). $\mathrm{Pd} / \mathrm{C}$ (5\%, Degussa type E101 NO/W, $100 \mathrm{mg}$ ) was added to a solution of $7(109 \mathrm{mg}, 0.160 \mathrm{mmol})$ in ethyl acetate $(5 \mathrm{~mL})$. Hydrogen was passed through the stirred mixture for $1 \mathrm{~h}$, after which TLC analysis indicated the complete conversion of starting material into a compound with $R_{\mathrm{f}}=0.20(\mathrm{MeOH} / \mathrm{DCM}, 5: 95$, $\mathrm{v} / \mathrm{v})$. The mixture was passed over a short column containing a layer of glass wool and a layer of hyflo ${ }^{\circledR}$ and, finally, over a PTFE filter. Concentration of the filtrate in vacuo yielded 8 as a white solid $(94 \mathrm{mg} ; 100 \%)$. ${ }^{1} \mathrm{H}$ NMR $\left(\mathrm{CDCl}_{3}\right): \delta=1.48\left(\mathrm{~s}, 9 \mathrm{H}, \mathrm{CH}_{3}\right.$, $t \mathrm{Bu}$ ), 1.77 (br. s, 2H, NH ), 2.72 (t, 1H, H-1ax), 2.92 (m, 3H, H-1eq, H-2, H-5), 3.16 $(\mathrm{t}, 1 \mathrm{H}, \mathrm{H}-3 \mathrm{~J}=8.9 \mathrm{~Hz}), 3.30$ (d, 1H, Ha-acetyl, J=17.6 Hz), 3.51 (t, 1H, H-4, J = 9.1 Hz), 3.55 (dd, 1H, H-6), 3.59 (d, 1H, Hb-acetyl, J = 17.6 Hz), 3.72 (dd, 1H, H-6', J $6_{6,6^{\prime}}=10.6 \mathrm{~Hz}$, $\left.\mathrm{J}_{5,6^{\prime}}=3.2 \mathrm{~Hz}\right), 4.44-4.94\left(\mathrm{~m}, 6 \mathrm{H}, 3 \times \mathrm{CH}_{2} \mathrm{Bn}\right), 7.18-7.35(\mathrm{~m}, 15 \mathrm{H}, \mathrm{CH}$-arom Bn). ${ }^{13} \mathrm{C}\left\{{ }^{1} \mathrm{H}\right\}$ NMR $\left(\mathrm{CDCl}_{3}\right): \delta=28.22\left(\mathrm{CH}_{3} t \mathrm{Bu}\right), 52.64(\mathrm{C}-2), 54.43\left(\mathrm{CH}_{2}\right.$ tert-butyl acetate), 57.78 (C-1), 62.35 (C-5), 65.90 (C-6), 73.50, 74.71, $75.10\left(3 \times \mathrm{CH}_{2} \mathrm{Bn}\right), 79.67$ $(\mathrm{C}-4), 81.00(\mathrm{Cq} t \mathrm{Bu}), 88.52(\mathrm{C}-3), 127.59-128.52$ (CH-arom Bn), 137.70, 138.50, 
$138.78(3 \times \mathrm{Cq} \mathrm{Bn}), 170.55\left(\mathrm{C}=\mathrm{O}\right.$ tert-butyl acetyl). ES-MS; m/z: 547.5, $[\mathrm{M}+\mathrm{H}]^{+}$; monoisotopic MW calculated for $\mathrm{C}_{33} \mathrm{H}_{42} \mathrm{~N}_{2} \mathrm{O}_{5}=546.31$.

3,4,6-Tri-O-benzyl-1,5- $N$-[(O-tert-butyl-carboxymethyl)imino]-2-(tetradecanoyl) amino-1,2,5-trideoxy-D-glucitol (9). To a stirred mixture of myristic acid (92 mg, $0.403 \mathrm{mmol}$ ), PyBOP (231 mg, $0.605 \mathrm{mmol})$ and DiPEA $(76 \mu \mathrm{L}, 0.443 \mathrm{mmol})$ in DCM $(10 \mathrm{~mL})$ a solution of $8(200 \mathrm{mg}, 0.366 \mathrm{mmol})$ in DCM $(10 \mathrm{~mL})$ was added. After 30 min, TLC analysis indicated the complete conversion of starting material into a compound with $R_{\mathrm{f}}=0.89(\mathrm{MeOH} / \mathrm{DCM}, 5: 95, \mathrm{v} / \mathrm{v})$. The reaction mixture was diluted with DCM $(100 \mathrm{~mL})$ and washed with water $(1 \times 50 \mathrm{~mL})$. After drying over $\mathrm{MgSO}_{4}$, the organic layer was concentrated under reduced pressure. The crude product was purified by silica gel column chromatography. Elution was performed with hexane/ ethyl acetate $(80: 20 \rightarrow 60: 40, \mathrm{v} / \mathrm{v})$. Yield $228 \mathrm{mg}(89 \%) .{ }^{1} \mathrm{H}$ NMR $\left(\mathrm{CDCl}_{3}\right): \delta=0.88(\mathrm{t}$, $3 \mathrm{H}, \mathrm{CH}_{3}$ myristyl), $1.25\left(\mathrm{~m}, 20 \mathrm{H}, 10 \times \mathrm{CH}_{2}\right.$ myristyl), $1.48\left(\mathrm{~s}, 9 \mathrm{H}, 3 \times \mathrm{CH}_{3} t \mathrm{Bu}\right), 1.49$ (m, $2 \mathrm{H}, \mathrm{CH}_{2}$ myristyl), $1.94\left(\mathrm{~m}, 2 \mathrm{H}, \mathrm{CH}_{2}\right.$ myristyl), 2.57 (dd, $1 \mathrm{H}, \mathrm{H}-1 \mathrm{ax}, \mathrm{J}_{1 \mathrm{ax}, \text { leq }}=11.8$ $\left.\mathrm{Hz}, \mathrm{J}_{1 \mathrm{ax}, 2}=7.0 \mathrm{~Hz}\right), 3.15(\mathrm{~m}, 1 \mathrm{H}, \mathrm{H}-5), 3.17$ (dd, $1 \mathrm{H}, \mathrm{H}-1 \mathrm{eq}, \mathrm{J}_{1 \mathrm{ax}, 1 \mathrm{eq}}=11.8 \mathrm{~Hz}$, $\left.\mathrm{J}_{\text {leq, } 2}=3.8 \mathrm{~Hz}\right), 3.29(\mathrm{~d}, 1 \mathrm{H}, \mathrm{Ha}$-acetyl, $\mathrm{J}=17.7 \mathrm{~Hz}), 3.45(\mathrm{t}, 1 \mathrm{H}, \mathrm{H}-3), 3.52(\mathrm{dd}, 1 \mathrm{H}, \mathrm{H}-$ $\left.6, \mathrm{~J}_{6,6^{\prime}}=10.2 \mathrm{~Hz}, \mathrm{~J}_{5,6}=4.9 \mathrm{~Hz}\right), 3.54(\mathrm{~d}, 1 \mathrm{H}, \mathrm{Hb}$-acetyl, $\mathrm{J}=17.7 \mathrm{~Hz}), 3.60(\mathrm{t}, 1 \mathrm{H}, \mathrm{H}-4$, $\mathrm{J}=6.1), 3.77\left(\mathrm{dd}, 1 \mathrm{H}, \mathrm{H}-6^{\prime}, \mathrm{J}_{6,6^{\prime}}=10.3 \mathrm{~Hz}, \mathrm{~J}_{5,6^{\prime}}=4.9 \mathrm{~Hz}\right), 4.00(\mathrm{~m}, 1 \mathrm{H}, \mathrm{H}-2), 4.41-4.70$ $\left(\mathrm{m}, 6 \mathrm{H}, 3 \times \mathrm{CH}_{2} \mathrm{Bn}\right), 5.85\left(\mathrm{~d}, 1 \mathrm{H}, \mathrm{NH}, \mathrm{J}_{2, \mathrm{NH}}=7.1 \mathrm{~Hz}\right), 7.24-7.35(\mathrm{~m}, 15 \mathrm{H}, \mathrm{CH}$-arom Bn). ${ }^{13} \mathrm{C}\left\{{ }^{1} \mathrm{H}\right\}$ NMR $\left(\mathrm{CDCl}_{3}\right): \delta=14.15\left(\mathrm{CH}_{3}\right.$ myristyl $), 22.74-36.92\left(\mathrm{CH}_{2}\right.$ myristyl $)$, $28.21\left(\mathrm{CH}_{3} t \mathrm{Bu}\right), 48.30(\mathrm{C}-2), 51.15(\mathrm{C}-1), 55.67\left(\mathrm{CH}_{2}\right.$ acetyl), $61.51(\mathrm{C}-5), 66.28(\mathrm{C}-$ 6), 72.93, 73.31, $73.39\left(3 \times \mathrm{CH}_{2} \mathrm{Bn}\right), 77.73(\mathrm{C}-4), 78.97(\mathrm{C}-3), 80.80(\mathrm{Cq} t \mathrm{Bu}), 127.67-$ 128.59 (CH-arom Bn), 138.02, 138.41, $138.45(3 \times \mathrm{Cq} \mathrm{Bn}), 170.90(\mathrm{C}=\mathrm{O}$ acetyl $)$, $172.96\left(\mathrm{C}=\mathrm{O}\right.$ myristyl). ES-MS; m/z: 757.5, $[\mathrm{M}+\mathrm{H}]^{+}$; monoisotopic MW calculated for $\mathrm{C}_{47} \mathrm{H}_{68} \mathrm{~N}_{2} \mathrm{O}_{6}=756.5$.

3,4,6-Tri- $O$-benzyl-1,5- $N$-[(O-tert-butylcarboxymethyl)imino]-2-[(R)-3-(dodecanoyloxytetradecanoyl)]amino-1,2,5-trideoxy-D-glucitol $(10) . \quad(R)$-3-Dodecanoyloxytetradecanoic acid $(73 \mathrm{mg}, 0.171 \mathrm{mmol})$ was coupled with compound $8(94 \mathrm{mg}, 0.172$ mmol) as described for the preparation of compound 9. The crude product was purified by silica gel column chromatography; elution was performed with hexane/ethyl acetate $(80: 20 \rightarrow 60: 40, \mathrm{v} / \mathrm{v}) . R_{\mathrm{f}}=0.66$ (hexane/ethyl acetate, $\left.2: 1, \mathrm{v} / \mathrm{v}\right)$. Yield $115 \mathrm{mg}(70 \%) .{ }^{1} \mathrm{H}$ NMR $\left(\mathrm{CDCl}_{3}\right): \delta=0.88\left(\mathrm{~m}, 6 \mathrm{H}, 2 \times \mathrm{CH}_{3}\right.$ acyloxyacyl), $1.25\left(\mathrm{~m}, 34 \mathrm{H}, \mathrm{CH}_{2}\right.$ acyloxyacyl), $1.40\left(\mathrm{~s}, 9 \mathrm{H}, 3 \times \mathrm{CH}_{3} t \mathrm{Bu}\right), 1.55\left(\mathrm{~m}, 4 \mathrm{H}, 2 \times \mathrm{CH}_{2}\right.$ acyloxyacyl), $2.21(\mathrm{~m}, 4 \mathrm{H}$, $2 \times \mathrm{CH}_{2}$ acyloxyacyl), $2.56\left(\mathrm{dd}, 1 \mathrm{H}, \mathrm{H}-1 \mathrm{ax}, \mathrm{J}_{1 \mathrm{ax}, \mathrm{eq}}=11.7 \mathrm{~Hz}, \mathrm{~J}_{1 \mathrm{ax}, 2}=7.3 \mathrm{~Hz}\right), 3.12(\mathrm{~m}$, 2H, H-1eq, H-5), 3.28 (d, 1H, Ha-acetyl, J=17.8 Hz), 3.45 (t, 1H, H-3, J=6.5 Hz), $3.53\left(\mathrm{dd}, 1 \mathrm{H}, \mathrm{H}-6, \mathrm{~J}_{6,6^{\prime}}=10.3 \mathrm{~Hz}, \mathrm{~J}_{5,6}=3.6 \mathrm{~Hz}\right), 3.55(\mathrm{~d}, 1 \mathrm{H}, \mathrm{Hb}$-acetyl, $\mathrm{J}=17.8 \mathrm{~Hz})$, $3.60(\mathrm{t}, 1 \mathrm{H}, \mathrm{H}-4, \mathrm{~J}=6.3 \mathrm{~Hz}), 3.76\left(\mathrm{dd}, 1 \mathrm{H}, \mathrm{H}-6^{\prime}, \mathrm{J}_{6,6^{\prime}}=10.3 \mathrm{~Hz}, \mathrm{~J}_{5,6^{\prime}}=5.0 \mathrm{~Hz}\right), 4.00(\mathrm{~m}$, $1 \mathrm{H}, \mathrm{H}-2), 4.40-4.71\left(\mathrm{~m}, 6 \mathrm{H}, 3 \times \mathrm{CH}_{2} \mathrm{Bn}\right), 5.11(\mathrm{~m}, 1 \mathrm{H}, \mathrm{CHO}$ acyloxyacyl), $6.06(\mathrm{~d}$, $\left.1 \mathrm{H}, \mathrm{NH}, \mathrm{J}_{2, \mathrm{NH}}=7.5 \mathrm{~Hz}\right), 7.23-7.33\left(\mathrm{~m}, 15 \mathrm{H}, \mathrm{CH}\right.$-arom Bn). $\left.{ }^{13} \mathrm{C}^{1}{ }^{1} \mathrm{H}\right\}$ NMR $\left(\mathrm{CDCl}_{3}\right)$ : $\delta=14.12\left(\mathrm{CH}_{3}\right.$ acyloxyacyl $), 22.70-41.65\left(\mathrm{CH}_{2}\right.$ acyloxyacyl $), 28.17\left(\mathrm{CH}_{3} t \mathrm{Bu}\right), 48.48$ (C-2), 51.30 (C-1), $55.52\left(\mathrm{CH}_{2}\right.$ acetyl), 61.43 (C-5), 66.27 (C-6), 71.21 (CHO acyloxyacyl), 72.92, 73.05, $73.34\left(3 \times \mathrm{CH}_{2} \mathrm{Bn}\right), 77.64(\mathrm{C}-4), 79.33(\mathrm{C}-3), 80.77(\mathrm{Cq}$ $t \mathrm{Bu}), 127.63-128.54(\mathrm{CH}-a$ rom $\mathrm{Bn}), 137.98,138.40,138.45(3 \times \mathrm{Cq} \mathrm{Bn}), 169.43$, 170.82, $173.12(3 \times \mathrm{C}=\mathrm{O}$ amide, ester $)$. ES-MS; $m / z: 954.67[\mathrm{M}+\mathrm{H}]^{+}$, monoisotopic MW calculated for $\mathrm{C}_{59} \mathrm{H}_{90} \mathrm{~N}_{2} \mathrm{O}_{8}=955.63$. 
3,4,6-Tri- $O$-benzyl-1,5- $N$-[carboxymethylimino]-2-(tetradecanoyl)amino-1,2,5-trideoxy-D-glucitol (11). A solution of $9(118 \mathrm{mg}, 0.156 \mathrm{mmol})$ in TFA $(5 \mathrm{~mL})$ was stirred for $2 \mathrm{~h}$ at ambient temperature, after which TLC analysis indicated complete conversion of starting material into a compound with $R_{\mathrm{f}}=0.12(\mathrm{MeOH} / \mathrm{DCM}, 5: 95$, $\mathrm{v} / \mathrm{v})$. After concentration of the reaction mixture, the residue was coevaporated with toluene $(3 \times 5 \mathrm{~mL})$. Yield $125 \mathrm{mg}$ (quantitative). ${ }^{1} \mathrm{H} \mathrm{NMR}\left(\mathrm{CDCl}_{3}\right): \delta=0.88(\mathrm{t}, 3 \mathrm{H}$, $\mathrm{CH}_{3}$ myristyl), 1.25 (m, 20H, $\mathrm{CH}_{2}$ myristyl), 1.48 (br. s, $2 \mathrm{H}, \mathrm{CH}_{2}$ myristyl), 2.04 (m, 2H, $\mathrm{CH}_{2}$ myristyl), 2.95 (d, 1H, H-1ax), 3.26 (br. s, 2H, H-1eq, H-5), 3.45 (br. s, 1H, Ha-acetyl), 3.56 (br. s, 2H, H-3, H-6), 3.72 (m, 2H, Hb-acetyl, H-6'), 3.89 (m, 1H, H4), 4.26 (br. s, $1 \mathrm{H}, \mathrm{H}-2$ ), $4.39-4.62$ (m, $6 \mathrm{H}, 3 \times \mathrm{CH}_{2} \mathrm{Bn}$ ), 7.09 (br. s, $1 \mathrm{H}, \mathrm{NH}$ ), $7.14-$ $7.27(\mathrm{~m}, 15 \mathrm{H}, \mathrm{CH}$-arom $\mathrm{Bn}), 9.40$ (br. s, $1 \mathrm{H}, \mathrm{COOH}) .{ }^{13} \mathrm{C}\left\{{ }^{1} \mathrm{H}\right\}$ NMR $\left(\mathrm{CDCl}_{3}\right)$ : $\delta=14.15\left(\mathrm{CH}_{3}\right.$ myristyl), 22.73-36.68 $\left(\mathrm{CH}_{2}\right.$ myristyl), $46.32(\mathrm{C}-2), 50(\mathrm{C}-1), 54.46$ $\left(\mathrm{CH}_{2}\right.$ acetyl), 61.08 (C-5), $64.88(\mathrm{C}-6), 73.10,73.33,73.49\left(3 \times \mathrm{CH}_{2} \mathrm{Bn}\right), 75.38(\mathrm{C}-4)$, 76.05(C-3), 127.82-128.71 (CH-arom Bn), 136.42-137.77 (Cq Bn), 165.08 (C=O carboxymethyl), $174.39\left(\mathrm{C}=\mathrm{O}\right.$ myristyl). ES-MS; $m / z: 701.5,[\mathrm{M}+\mathrm{H}]^{+}$; monoisotopic MW calculated for $\mathrm{C}_{43} \mathrm{H}_{60} \mathrm{~N}_{2} \mathrm{O}_{6}=700.45$.

3,4,6-Tri-O-benzyl-1,5- $N$-[carboxymethylimino]-2-[(R)-3-(dodecanoyloxytetradecanoyl)]amino-1,2,5-trideoxy-D-glucitol (12). Compound 10 (115 mg, $0.120 \mathrm{mmol})$ was treated with TFA as described for the preparation of compound 11. The crude product was purified by silica gel column chromatography. Elution was performed with $\mathrm{MeOH} / \mathrm{DCM}(0: 100 \rightarrow 5: 95, \mathrm{v} / \mathrm{v}) . R_{\mathrm{f}}=0.12$ (hexane/ethyl acetate, 1:2, v/v). Yield $90 \mathrm{mg}(83 \%) .{ }^{1} \mathrm{H}$ NMR $\left(\mathrm{CDCl}_{3}\right): \delta=0.88\left(\mathrm{~m}, 6 \mathrm{H}, 2 \times \mathrm{CH}_{3}\right.$ acyloxyacyl), 1.25 (br. s, $34 \mathrm{H}, \mathrm{CH}_{2}$ acyloxyacyl), $1.56\left(\mathrm{~m}, 4 \mathrm{H}, \mathrm{CH}_{2}\right.$ acyloxyacyl $), 2.23\left(\mathrm{~m}, 4 \mathrm{H}, \mathrm{CH}_{2}\right.$ acyloxyacyl), 2.60 (d, 1H, H-1ax), 3.21 (m, 2H, H-1eq, H-5), 3.40 (d, 1H, Ha-acetyl), 3.51 (m, 2H, H-3, H-6), 3.66 (m, 2H, Hb-acetyl, H-6'), 3.86 (m, 1H, H-4), 4.13 (br. s, 1H, $\mathrm{H}-2)$, 4.39-4.62 (m, 6H, $\left.3 \times \mathrm{CH}_{2} \mathrm{Bn}\right), 5.05$ (m, 1H, CHO acyloxyacyl), 6.70 (br. s, $1 \mathrm{H}$, $\mathrm{NH}), 7.21-7.35\left(\mathrm{~m}, 15 \mathrm{H}, \mathrm{CH}\right.$-arom Bn). ${ }^{13} \mathrm{C}\left\{{ }^{1} \mathrm{H}\right\}$ NMR $\left(\mathrm{CDCl}_{3}\right): \delta=14.13\left(\mathrm{CH}_{3}\right.$ acyloxyacyl), 22.71-41.86 ( $\mathrm{CH}_{2}$ acyloxyacyl), 47.03 (C-2), 49.49 (C-1), $56.66\left(\mathrm{CH}_{2}\right.$ acetyl), 61.56 (C-5), 65.94 (C-6), 71.09 (CHO acyloxyacyl), 72.72, 73.12, 73.45 ( $3 \times \mathrm{CH}_{2} \mathrm{Bn}$ ), 75.83 (C-4), 76.08 (C-3), 127.69-128.70 (CH-arom Bn), 137.27, 137.46, $137.68(3 \times \mathrm{Cq} \mathrm{Bn}), 169.49,171.96,173.45(3 \times \mathrm{C}=\mathrm{O}$ acid, amide, ester). ES-MS; $\mathrm{m} / \mathrm{z}$ : 899.7, $[\mathrm{M}+\mathrm{H}]^{+}$; monoisotopic MW calculated for $\mathrm{C}_{55} \mathrm{H}_{82} \mathrm{~N}_{2} \mathrm{O}_{8}=898.6$.

Methyl 2-[(benzyloxycarbonyl)amino]-2-deoxy- $\alpha$-D-glucopyranoside (15). To a cooled $\left(0^{\circ} \mathrm{C}\right)$ solution of glucosamine hydrochloride $(\mathbf{1 3})(20 \mathrm{~g}, 93 \mathrm{mmol})$ in water $(400 \mathrm{~mL}) \mathrm{NaHCO}_{3}(14.4 \mathrm{~g}, 171 \mathrm{mmol})$ and benzyl chloroformate $(17.4 \mathrm{~mL}, 104 \mathrm{mmol})$ were added. The mixture was stirred at ambient temperature for $16 \mathrm{~h}$, after which the white crystalline residue (14) was filtered off, washed with cold acetone $\left(-20^{\circ} \mathrm{C}\right)$ and dried. The white crystals were dissolved in acidic methanol $(2 \% \mathrm{HCl}, \mathrm{w} / \mathrm{w})$ and refluxed for $7 \mathrm{~h}$ after which the reaction mixture was concentrated. The resulting residue was purified by silica gel column chromatography. Elution was performed with $\mathrm{MeOH} / \mathrm{DCM}(10: 90 \rightarrow 15: 85, \mathrm{v} / \mathrm{v})$. Yield $16 \mathrm{~g}(53 \%)$. $R_{\mathrm{f}}=0.70(\mathrm{MeOH} / \mathrm{DCM}, 15: 85$, v/v). ${ }^{1} \mathrm{H}$ NMR (DMSO-d $\mathrm{d}_{6}$ ): $\delta=3.16(\mathrm{~m}, 2 \mathrm{H}, \mathrm{H}-4, \mathrm{H}-5), 3.27$ (s, 3H, OMe), $3.46(\mathrm{~m}$, $\left.3 \mathrm{H}, \mathrm{H}-2, \mathrm{H}_{2}-6\right), 3.67$ (m, 1H, H-3), 4.51 (t, 1H, OH-6), 4.61 (d, 1H, H-1, J $\mathrm{J}_{1,2}=3.2 \mathrm{~Hz}$ ), $4.76(\mathrm{~d}, 1 \mathrm{H}, \mathrm{OH}-3), 4.98$ (d, 1H, OH-4), 5.04 (dd, 2H, $\left.\mathrm{CH}_{2} \mathrm{Z}\right), 7.07$ (d, 1H, NH, $\left.\mathrm{J}_{2, \mathrm{NH}}=7.7 \mathrm{~Hz}\right), 7.31-7.42(\mathrm{~m}, 5 \mathrm{H}, \mathrm{CH}-\operatorname{arom~Z}) .{ }^{13} \mathrm{C}\left\{{ }^{1} \mathrm{H}\right\}$ NMR $($ DMSO-d 6 ): $\delta=54.37$ 
(OMe), 55.95 (C-2), 60.89 (C-6), $65.34\left(\mathrm{CH}_{2} \mathrm{Z}\right), 70.65$ (C-5), $70.81(\mathrm{C}-3), 72.72(\mathrm{C}-4)$, 98.09 (C-1), 127.78, 128.35 (CH-arom Z), $137.16(\mathrm{Cq} \mathrm{Z}), 156.17(\mathrm{C}=\mathrm{O} \mathrm{Z})$.

Methyl 2-[(benzyloxycarbonyl)amino]-2-deoxy-4,6- $O$-isopropylidene- $\alpha$-D-glucopyranoside (16). To a mixture of $15(16 \mathrm{~g}, 49 \mathrm{mmol})$ in dry acetone $(200 \mathrm{~mL})$ and DCM $(150 \mathrm{~mL})$ was added 2,2-dimethoxypropane $(25 \mathrm{~mL}, 204 \mathrm{mmol})$ and $p$-toluene sulfonic acid $(0.4 \mathrm{~g}, 2.1 \mathrm{mmol})$. The resulting mixture was stirred at ambient temperature and after $16 \mathrm{~h}$, TLC analysis showed complete conversion of starting material into a compound with $R_{\mathrm{f}}=0.80(\mathrm{MeOH} / \mathrm{DCM}, 5: 95$, v/v). TEA $(5 \mathrm{~mL})$ and DCM $(100 \mathrm{~mL})$ were added and the mixture was washed with water $(50 \mathrm{~mL})$. The organic layer was dried $\left(\mathrm{MgSO}_{4}\right)$ and concentrated. Purification of the crude product by silica gel column chromatography (elution with $\mathrm{MeOH} / \mathrm{DCM}(0: 100 \rightarrow 5: 95$, v/v)), yielded $18 \mathrm{~g}$ (quantitative) of a yellow oil. ${ }^{1} \mathrm{H}$ NMR $\left(\mathrm{CDCl}_{3}\right): \delta=1.42\left(\mathrm{~s}, 3 \mathrm{H}, \mathrm{CH}_{3}\right.$ isopropylidene), 1.51 (s, $3 \mathrm{H}, \mathrm{CH}_{3}$ isopropylidene), 2.84 (s, 1H, OH-3), 3.33 (s, 3H, OMe), 3.59 (m, $2 \mathrm{H}, \mathrm{H}-4$, H-5), 3.74 (m, 2H, H-3, H-6), 3.87 (m, 2H, H-2, H-6'), 4.68 (d, 1H, H-1, J $\mathrm{J}_{1,2}=3.4 \mathrm{~Hz}$ ), $5.11\left(\mathrm{~s}, 2 \mathrm{H}, \mathrm{CH}_{2} \mathrm{Z}\right), 5.19\left(\mathrm{~d}, 1 \mathrm{H}, \mathrm{NH}, \mathrm{J}_{2, \mathrm{NH}}=8.7 \mathrm{~Hz}\right), 7.32-7.36(\mathrm{~m}, 5 \mathrm{H}, \mathrm{CH}$-arom Z). ${ }^{13} \mathrm{C}\left\{{ }^{1} \mathrm{H}\right\}$ NMR $\left(\mathrm{CDCl}_{3}\right): \delta=19.17,29.14\left(2 \times \mathrm{CH}_{3}\right.$ isopropylidene $), 55.28(\mathrm{OMe})$, 55.92 (C-2), 62.36 (C-6), 63.36 (C-5), $67.30\left(\mathrm{CH}_{2} \mathrm{Z}\right), 70.88$ (C-3), 74.63 (C-4), 99.23 (C-1), 99.90 (Cq isopropylidene), 128.09-128.60 (CH-arom Z), 136.22 (Cq Z), 156.87 $(\mathrm{C}=\mathrm{O} \mathrm{Z})$.

Methyl 2-[(benzyloxycarbonyl)amino]-2-deoxy-4,6- $O$-isopropylidene-3- $O$-tetradecanoyl- $\alpha$-D-glucopyranoside (17). To a solution of $16(5.545 \mathrm{~g}, 15.10 \mathrm{mmol})$ in DCM was added DMAP (2.03 g, $16.6 \mathrm{mmol})$, myristic acid $(3.79 \mathrm{~g}, 16.6 \mathrm{mmol})$ and DCC (3.43 g, $16.6 \mathrm{mmol})$. The reaction mixture was stirred for $18 \mathrm{~h}$ at ambient temperature. TLC analysis (MeOH/DCM, 1:99, v/v) showed complete conversion of starting material into a compound with $R_{\mathrm{f}}=0.91$. DCU was filtered off and the filter was washed with DCM $(3 \times 25 \mathrm{~mL})$. DCM was concentrated and the crude product was purified by silica gel column chromatography. Elution was performed with $\mathrm{MeOH} / \mathrm{DCM}$ $(0: 100 \rightarrow 3: 97, \mathrm{v} / \mathrm{v})$. Yield: $7.49 \mathrm{~g}(86 \%)$ of a colorless oil. ${ }^{1} \mathrm{H}$ NMR $\left(\mathrm{CDCl}_{3}\right): \delta=0.88(\mathrm{t}$, $3 \mathrm{H}, \mathrm{CH}_{3}$ myristyl), 1.25 (br. s, $20 \mathrm{H}, \mathrm{CH}_{2}$ myristyl), 1.36 (s, $3 \mathrm{H}, \mathrm{CH}_{3}$ isopropylidene), $1.46\left(\mathrm{~s}, 3 \mathrm{H}, \mathrm{CH}_{3}\right.$ isopropylidene), $1.54\left(\mathrm{~m}, 2 \mathrm{H}, \mathrm{CH}_{2}\right.$ myristyl), $2.22\left(\mathrm{~m}, 2 \mathrm{H}, \mathrm{CH}_{2}\right.$ myristyl), 3.36 (s, 3H, OMe), 3.69 (m, 2H, H-4, H-5), 3.76 (t, 1H, H-6), 3.87 (dd, 1H, H$\left.6^{\prime}, \mathrm{J}_{5,6^{\prime}}=4.7 \mathrm{~Hz}, \mathrm{~J}_{6,6^{\prime}}=10.2 \mathrm{~Hz}\right), 3.97\left(\mathrm{~m}, 1 \mathrm{H}, \mathrm{H}-2, \mathrm{~J}_{1,2}=3.7 \mathrm{~Hz}, \mathrm{~J}=10.2 \mathrm{~Hz}\right), 4.69(\mathrm{~d}$, $\left.1 \mathrm{H}, \mathrm{H}-1, \mathrm{~J}_{1,2}=3.7 \mathrm{~Hz}\right), 5.06\left(\mathrm{~s}, 2 \mathrm{H}, \mathrm{CH}_{2} \mathrm{Z}\right), 5.12(\mathrm{~m}, 2 \mathrm{H}, \mathrm{H}-3, \mathrm{NH}), 7.26-7.36(\mathrm{~m}, 5 \mathrm{H}$, $\mathrm{CH}$-arom Z). ${ }^{13} \mathrm{C}\left\{{ }^{1} \mathrm{H}\right\}$ NMR $\left(\mathrm{CDCl}_{3}\right): \delta=14.15\left(\mathrm{CH}_{3}\right.$ myristyl $), 19.11,29.11\left(2 \times \mathrm{CH}_{3}\right.$ isopropylidene), 22.74-34.38 ( $\mathrm{CH}_{2}$ myristyl), $54.60(\mathrm{C}-2), 55.32(\mathrm{OMe}), 62.51$ (C-6), 63.86 (C-5), $66.93\left(\mathrm{CH}_{2} \mathrm{Z}\right), 70.36$ (C-3), 72.15 (C-4), 99.43 (C-1), 99.73 (Cq isopropylidene), 128.03, 128.18, $128.55(\mathrm{CH}$-arom $\mathrm{Z}), 136.40(\mathrm{Cq} \mathrm{Z}), 156.01(\mathrm{C}=\mathrm{O} \mathrm{Z})$, $173.83(\mathrm{C}=\mathrm{O}$ ester $)$.

Methyl 2-amino-2-deoxy-4,6- $O$-isopropylidene-3- $O$-tetradecanoyl- $\alpha$-D-glucopyranoside (18). To a solution of $17(6.69 \mathrm{~g}, 11.6 \mathrm{mmol})$ in EtOAc $(100 \mathrm{~mL})$ was added $\mathrm{Pd} / \mathrm{C}(10 \%, 1.0 \mathrm{~g})$. Hydrogen was passed through the stirred mixture for $66 \mathrm{~h}$. TLC analysis showed complete conversion of starting material into a new product with $R_{\mathrm{f}}=0.26(\mathrm{MeOH} / \mathrm{DCM}, 1: 99, \mathrm{v} / \mathrm{v})$. The mixture was filtered over a PTFE filter. The filtrate was concentrated under reduced pressure. Yield: $5.19 \mathrm{~g}$ (quantitative) of a 
colorless oil. ${ }^{1} \mathrm{H}$ NMR $\left(\mathrm{CDCl}_{3}\right): \delta=0.88$ (s, $3 \mathrm{H}, \mathrm{t}, \mathrm{CH}_{3}$ myristyl), 1.25 (br. s, $20 \mathrm{H}$, $\mathrm{CH}_{2}$ myristyl), 1.36 (s, $3 \mathrm{H}, \mathrm{CH}_{3}$ isopropylidene), 1.45 (s, $3 \mathrm{H}, \mathrm{CH}_{3}$ isopropylidene), $1.64\left(\mathrm{~m}, 2 \mathrm{H}, \mathrm{CH}_{2}\right.$ myristyl), $1.76\left(\mathrm{~m}, 2 \mathrm{H}, \mathrm{NH}_{2}\right), 2.34\left(\mathrm{q}, 2 \mathrm{H}, \mathrm{CH}_{2}\right.$ myristyl), 2.86 $\left(\mathrm{dd}, 1 \mathrm{H}, \mathrm{H}-2, \mathrm{~J}_{1,2}=3.6 \mathrm{~Hz}, \mathrm{~J}_{2,3}=10.0 \mathrm{~Hz}\right), 3.39(\mathrm{~s}, 3 \mathrm{H}, \mathrm{OMe}), 3.56(\mathrm{~d}, 1 \mathrm{H}, \mathrm{H}-4), 3.72$ $(\mathrm{m}, 2 \mathrm{H}, \mathrm{H}-5, \mathrm{H}-6), 3.87\left(\mathrm{~m}, 1 \mathrm{H}, \mathrm{H}-6^{\prime}\right), 4.71\left(\mathrm{~d}, 1 \mathrm{H}, \mathrm{H}-1, \mathrm{~J}_{1,2}=3.6 \mathrm{~Hz}\right), 5.05(\mathrm{t}, 1 \mathrm{H}$, $\mathrm{H}-3) .{ }^{13} \mathrm{C}\left\{{ }^{1} \mathrm{H}\right\} \quad \mathrm{NMR}\left(\mathrm{CDCl}_{3}\right): \delta=14.11\left(\mathrm{CH}_{3}\right.$ myristyl $), 19.09,29.13\left(2 \times \mathrm{CH}_{3}\right.$ isopropylidene), 22.70-34.61 ( $\mathrm{CH}_{2}$ myristyl), 55.29 (OMe), 55.54 (C-2), 62.64 (C-6), 63.83 (C-5), 72.50 (C-4), 73.76 (C-3), 99.52 (Cq isopropylidene), 101.37 (C-1), 173.63 $(\mathrm{C}=\mathrm{O}$ ester $)$.

Methyl 2-[(6-benzyloxycarbonylamino)hexanoylamino]-2-deoxy-4,6-O-isopropylidene-3- $O$-tetradecanoyl- $\alpha$-D-glucopyranoside (22). To a stirred mixture of 6-benzyloxycarbonylaminohexanoic acid (19; $516 \mathrm{mg}, 1.95 \mathrm{mmol})$, PyBOP (1.522 g, 2.93 mmol) and DiPEA $(367 \mu \mathrm{L}, 2.15 \mathrm{mmol})$ in DCM $(50 \mathrm{~mL})$ was added $18(0.913 \mathrm{~g}, 2.06$ $\mathrm{mmol})$ in DCM $(10 \mathrm{~mL})$. After $1 \mathrm{~h}$, TLC analysis indicated the complete conversion of starting material into a product with $R_{\mathrm{f}}=0.57$ (hexane/ethyl acetate, $1: 2, \mathrm{v} / \mathrm{v}$ ). The reaction mixture was diluted with DCM $(100 \mathrm{~mL})$ and washed with water $(3 \times 50 \mathrm{~mL})$. The organic layer was dried $\left(\mathrm{MgSO}_{4}\right)$ and concentrated under reduced pressure. The crude product was purified by silica gel column chromatography. Elution was performed with hexane/ethyl acetate $(60: 40 \rightarrow 40: 60, \mathrm{v} / \mathrm{v})$. Yield $1.172 \mathrm{~g}(87 \%) .{ }^{1} \mathrm{H}$ NMR $\left(\mathrm{CDCl}_{3}\right): \delta=0.88$ (t, 3H, $\mathrm{CH}_{3}$ myristyl), $1.23-1.64\left(\mathrm{~m}, 28 \mathrm{H}, \mathrm{CH}_{2}\right.$ hexanoyl, myristyl), 1.37 (s, $3 \mathrm{H}, \mathrm{CH}_{3}$ isopropylidene), 1.47 (s, $3 \mathrm{H}, \mathrm{CH}_{3}$ isopropylidene), $2.11-2.35(\mathrm{~m}, 4 \mathrm{H}$, hexanoyl, myristyl), 3.17 (br. q, $2 \mathrm{H}, \mathrm{CH}_{2}$ hexanoyl), 3.35 (s, 3H, OMe), 3.66-3.79 (m, $3 \mathrm{H}, \mathrm{H}-4, \mathrm{H}-5, \mathrm{H}-6), 3.87$ (dd, 1H, H-6', $\left.\mathrm{J}_{5,6^{\prime}}=5.0 \mathrm{~Hz}, \mathrm{~J}_{6,6^{\prime}}=10.5 \mathrm{~Hz}\right), 4.27$ (m, 1H, H-2, $\left.\mathrm{J}_{1,2}=3.7 \mathrm{~Hz}, \mathrm{~J}_{2,3}=9.5 \mathrm{~Hz}\right), 4.66\left(\mathrm{~d}, 1 \mathrm{H}, \mathrm{H}-1 \mathrm{~J}_{1,2}=3.7 \mathrm{~Hz}\right), 4.95(\mathrm{~s}, 1 \mathrm{H}, \mathrm{NH}$ aminohexanoyl), 5.09 (s, 2H, CH $\mathrm{Z}$ ), $5.12\left(\mathrm{t}, 1 \mathrm{H}, \mathrm{H}-3, \mathrm{~J}_{2,3}=9.5 \mathrm{~Hz}, \mathrm{~J}_{3,4}=9.5 \mathrm{~Hz}\right), 5.88(\mathrm{~s}$, $1 \mathrm{H}, \mathrm{NH}), 7.28-7.35\left(\mathrm{~m}, 5 \mathrm{H}, \mathrm{CH}\right.$-arom Z). ${ }^{13} \mathrm{C}\left\{{ }^{1} \mathrm{H}\right\}$ NMR $\left(\mathrm{CDCl}_{3}\right): \delta=14.08\left(\mathrm{CH}_{3}\right.$ myristyl), 22.66-40.82 $\left(\mathrm{CH}_{2}\right.$ hexanoyl, myristyl), $19.06,26.23\left(2 \times \mathrm{CH}_{3}\right.$ isopropylidene), 52.51 (C-2), $55.23(\mathrm{OMe}), 62.43(\mathrm{C}-6), 63.73(\mathrm{C}-5), 66.55\left(\mathrm{CH}_{2} \mathrm{Z}\right), 70.38(\mathrm{C}-3)$, 71.94 (C-4), 99.07 (C-1), 99.73 (Cq isopropylidene), 128.03, 128.48 (CH-arom Z), $136.72(\mathrm{Cq} \mathrm{Z}), 156.21(\mathrm{C}=\mathrm{O} \mathrm{Z}), 172.82,174.26(2 \times \mathrm{C}=\mathrm{O}$ amide, ester $)$.

Methyl 2-[(12-benzyloxycarbonylamino)dodecanoylamino]-2-deoxy-4,6-O-isopropylidene-3- $\boldsymbol{O}$-tetradecanoyl- $\alpha$-D-glucopyranoside (23). 12-Benzyloxycarbonylaminododecanoic acid $20(0.642 \mathrm{~g}, 1.84 \mathrm{mmol})$ was coupled with compound $18(0.815 \mathrm{~g}$, $1.84 \mathrm{mmol}$ ) as described for the preparation of compound 22. The crude product was purified by silica gel column chromatography. Elution was performed with hexane/ ethyl acetate $(90: 10 \rightarrow 40: 60, \mathrm{v} / \mathrm{v})$. Yield $1.368 \mathrm{~g}(96 \%) .{ }^{1} \mathrm{H}$ NMR $\left(\mathrm{CDCl}_{3}\right): \delta=0.88(\mathrm{t}$, $3 \mathrm{H}, \mathrm{CH}_{3}$ myristyl), 1.25 (m, $34 \mathrm{H}, \mathrm{CH}_{2}$ dodecanoyl, myristyl), 1.37 (s, $3 \mathrm{H}, \mathrm{CH}_{3}$ isopropylidene), $1.46\left(\mathrm{~s}, 3 \mathrm{H}, \mathrm{CH}_{3}\right.$ isopropylidene $), 1.57\left(\mathrm{~m}, 6 \mathrm{H}, \mathrm{CH}_{2}\right.$ dodecanoyl, myristyl), 2.10-2.33 (m, 4H, dodecanoyl, myristyl), 3.17 (q, 2H, $\mathrm{CH}_{2}$ dodecanoyl), 3.36 (s, 3H, OMe), 3.69-3.79 (m, 3H, H-4, H-5, H-6), 3.87 (dd, 1H, H-6'), 4.27 (m, $1 \mathrm{H}, \mathrm{H}-2), 4.67\left(\mathrm{~d}, 1 \mathrm{H}, \mathrm{H}-1, \mathrm{~J}_{1,2}=3.6 \mathrm{~Hz}\right), 4.82(\mathrm{~s}, 1 \mathrm{H}, \mathrm{NH}$ aminododecanoyl), 5.09 (s, $2 \mathrm{H}, \mathrm{CH}_{2} \mathrm{Z}$ ), 5.13 (q, 1H, H-3), $5.82(\mathrm{~d}, 1 \mathrm{H}, \mathrm{NH}), 7.27-7.35$ (m, 5H, CH-arom Z). ${ }^{13} \mathrm{C}\left\{{ }^{1} \mathrm{H}\right\}$ NMR $\left(\mathrm{CDCl}_{3}\right): \delta=14.11\left(\mathrm{CH}_{3}\right.$ myristyl $), 22.68-41.15\left(\mathrm{CH}_{2}\right.$ dodecanoyl, myristyl), 19.07, $29.07\left(2 \times \mathrm{CH}_{3}\right.$ isopropylidene), 52.49 (C-2), $55.25(\mathrm{OMe}), 62.46(\mathrm{C}-$ 6), 63.78 (C-5), $66.55\left(\mathrm{CH}_{2} \mathrm{Z}\right), 70.28$ (C-3), 71.97 (C-4), $99.13(\mathrm{C}-1), 99.74(\mathrm{Cq}$ 
isopropylidene), 128.04, 128.49 (CH-arom Z), 136.5 (Cq Z), $156.5(\mathrm{C}=\mathrm{O} \mathrm{Z}), 173.14$, $174.23(2 \times \mathrm{C}=\mathrm{O}$ amide, ester $)$.

Methyl 2-[(R)-3-(6-benzyloxycarbonylamino)hexanoyloxytetradecanoylamino]-2deoxy-4,6- $O$-isopropylidene-3- $O$-tetradecanoyl- $\alpha$-D-glucopyranoside (24). $\quad(R)-3$-(6Benzyloxycarbonylamino)hexanoyloxytetradecanoic acid 21 (0.516 g, $1.95 \mathrm{mmol})$ was coupled with compound $18(0.913 \mathrm{~g}, 2.06 \mathrm{mmol})$ as described for the preparation of compound 22. The crude product was purified by silica gel column chromatography. Elution was performed with hexane/ethyl acetate $(80: 20 \rightarrow 30: 70, \mathrm{v} / \mathrm{v})$. Yield $1.172 \mathrm{~g}$ (87\%). ${ }^{1} \mathrm{H}$ NMR $\left(\mathrm{CDCl}_{3}\right): \delta=0.88\left(\mathrm{t}, 6 \mathrm{H}, \mathrm{CH}_{3}\right.$ acyloxyacyl, myristyl), 1.25-1.67 (m, $48 \mathrm{H}, \mathrm{CH}_{2}$ acyloxyacyl, myristyl), $1.36\left(\mathrm{~s}, 3 \mathrm{H}, \mathrm{CH}_{3}\right.$ isopropylidene), $1.46\left(\mathrm{~s}, 3 \mathrm{H}, \mathrm{CH}_{3}\right.$ isopropylidene), $2.24-2.45$ ( $\mathrm{m}, 6 \mathrm{H}$, acyloxyacyl, myristyl), 3.17 (q, $2 \mathrm{H}, \mathrm{CH}_{2}$ hexanoyl), 3.34 (s, 3H, OMe), 3.66-3.78 (m, 3H, H-4, H-5, H-6), 3.87 (dd, 1H, H-6'), 4.24 (m, $1 \mathrm{H}, \mathrm{H}-2), 4.66\left(\mathrm{~d}, 1 \mathrm{H}, \mathrm{H}-1, \mathrm{~J}_{1,2}=3.7 \mathrm{~Hz}\right), 4.92(\mathrm{~s}, 1 \mathrm{H}, \mathrm{NH}$ aminohexanoyl), $5.09(\mathrm{~m}$, $4 \mathrm{H}, \mathrm{CH}_{2} \mathrm{Z}, \mathrm{H}-3, \mathrm{CHO}$ acyloxyacyl), $5.97(\mathrm{~d}, 1 \mathrm{H}, \mathrm{NH}), 7.27-7.35(\mathrm{~m}, 5 \mathrm{H}, \mathrm{CH}$-arom Z). ${ }^{13} \mathrm{C}\left\{{ }^{1} \mathrm{H}\right\}$ NMR $\left(\mathrm{CDCl}_{3}\right): \delta=14.12\left(\mathrm{CH}_{3}\right.$ myristyl $), 22.71-41.29\left(\mathrm{CH}_{2}\right.$ acyloxyacyl, myristyl), 19.10, $29.09\left(2 \times \mathrm{CH}_{3}\right.$ isopropylidene), 52.59 (C-2), 55.22 (OMe), 62.47 (C6), 63.79 (C-5), 66.59 ( $\left.\mathrm{CH}_{2} \mathrm{Z}\right), 70.27$ (C-3), 71.09 (CHO acyloxyacyl), 72.05 (C-4), 98.98 (C-1), 99.77 (Cq isopropylidene), 128.05, 128.52 (CH-arom Z), $156.45(\mathrm{C}=\mathrm{O} \mathrm{Z})$, $169.62,172.82,174.26(3 \times \mathrm{C}=\mathrm{O}$ amide, ester $)$.

Methyl 2-[(6-benzyloxycarbonylamino)hexanoylamino]-2-deoxy-3-O-tetradecanoyl$\alpha$-D-glucopyranoside (25). To a stirred solution of $22(0.801 \mathrm{~g}, 1.16 \mathrm{mmol})$ in $\mathrm{THF} /$ water $(4: 1, \mathrm{v} / \mathrm{v} ; 25 \mathrm{~mL})$ at $0^{\circ} \mathrm{C}$ was added TFA $(1 \mathrm{~mL})$. The resulting solution was allowed to warm to room temperature and left overnight. TLC analysis (ethyl acetate/ hexane, 2:1, v/v) showed complete conversion of starting material into a compound with $R_{\mathrm{f}}=0.13$. The reaction mixture was concentrated under reduced pressure. The residue was diluted with diethyl ether $(100 \mathrm{~mL})$ and washed with water $(3 \times 50 \mathrm{~mL})$. The organic layer was dried over $\mathrm{Na}_{2} \mathrm{SO}_{4}$, and the solvent was removed under reduced pressure. Purification of the residue by silica gel column chromatography with DCM/ ethanol $(100: 0 \rightarrow 93: 7, \mathrm{v} / \mathrm{v})$ yielded the desired diol 25 as a colorless oil $(0.747 \mathrm{~g}$; 99\%). ${ }^{1} \mathrm{H}$ NMR $\left(\mathrm{CDCl}_{3}\right): \delta=0.88\left(\mathrm{t}, 3 \mathrm{H}, \mathrm{CH}_{3}\right.$ myristyl), $1.24\left(\mathrm{~m}, 22 \mathrm{H}, \mathrm{CH}_{2}\right.$ hexanoyl, myristyl), 1.54 (m, 6H, $\mathrm{CH}_{2}$ hexanoyl, myristyl), 2.13 (t, $2 \mathrm{H}, \mathrm{CH}_{2}$ hexanoyl, myristyl), $2.30\left(\mathrm{~m}, 2 \mathrm{H}, \mathrm{CH}_{2}\right.$ hexanoyl, myristyl), 3.17 (q, $2 \mathrm{H}, \mathrm{CH}_{2}$ hexanoyl), 3.37 (s, 3H, $\mathrm{OMe}$ ), $3.65\left(\mathrm{~m}, 1 \mathrm{H}, \mathrm{H}-5, \mathrm{~J}_{4,5}=9.7 \mathrm{~Hz}\right), 3.78\left(\mathrm{t}, 1 \mathrm{H}, \mathrm{H}-4, \mathrm{~J}_{3,4}=9.5 \mathrm{~Hz}, \mathrm{~J}_{4,5}=9.5 \mathrm{~Hz}\right), 3.86(\mathrm{~s}$, $\left.2 \mathrm{H}, \mathrm{H}_{2}-6\right), 4.20\left(\mathrm{~m}, 1 \mathrm{H}, \mathrm{H}-2, \mathrm{~J}_{1,2}=3.4 \mathrm{~Hz}, \mathrm{~J}_{2, \mathrm{NH}}=9.5 \mathrm{~Hz}, \mathrm{~J}_{2,3}=10.5 \mathrm{~Hz}\right), 4.70(\mathrm{~d}, 1 \mathrm{H}$, $\mathrm{H}-1, \mathrm{~J}_{1,2}=3.4 \mathrm{~Hz}$ ), 4.99 (br. s, $1 \mathrm{H}, \mathrm{NH}$ aminohexanoyl), 5.08 (br. s, $2 \mathrm{H}, \mathrm{CH}_{2} \mathrm{Z}$ ), 5.10 $\left(\mathrm{t}, 1 \mathrm{H}, \mathrm{H}-3, \mathrm{~J}_{2,3}=10.5 \mathrm{~Hz}, \mathrm{~J}_{3,4}=9.5 \mathrm{~Hz}\right), 5.99\left(\mathrm{~d}, 1 \mathrm{H}, \mathrm{NH}, \mathrm{J}_{2, \mathrm{NH}}=9.2 \mathrm{~Hz}\right), 7.27-7.36$ (m, 5H, CH-arom Z). ${ }^{13} \mathrm{C}\left\{{ }^{1} \mathrm{H}\right\}$ NMR $\left(\mathrm{CDCl}_{3}\right): \delta=14.11\left(\mathrm{CH}_{3}\right.$ myristyl), 22.71-40.83 $\left(\mathrm{CH}_{2}\right.$ hexanoyl, myristyl), $52.04(\mathrm{C}-2), 55.27(\mathrm{OMe}), 61.98(\mathrm{C}-6), 66.66\left(\mathrm{CH}_{2} \mathrm{Z}\right), 68.93$ (C-4), 71.52 (C-5), 73.78 (C-3), 98.49 (C-1), 128.11, 128.53 (CH-arom Z), $136.68(\mathrm{Cq}$ $\mathrm{Z}), 156.55(\mathrm{C}=\mathrm{O} \mathrm{Z}), 173.14,175.22(2 \times \mathrm{C}=\mathrm{O}$ amide, ester $)$.

Methyl 2-[(12-benzyloxycarbonylamino)dodecanoylamino]-2-deoxy-3- $O$-tetradecanoyl- $\boldsymbol{\alpha}$-D-glucopyranoside (26). Acetonide $23(1.368 \mathrm{~g}, 1.77 \mathrm{mmol})$ was treated with TFA as was described for the preparation of compound 25. Silica gel column chromatography with DCM/ethanol $(100: 0 \rightarrow 94: 6, \mathrm{v} / \mathrm{v})$ of the residue yielded the desired 
diol as a white solid $(0.816 \mathrm{~g} ; 63 \%) .{ }^{1} \mathrm{H}$ NMR $\left(\mathrm{CDCl}_{3}\right): \delta=0.88$ (t, $3 \mathrm{H}, \mathrm{CH}_{3}$ myristyl), 1.25 (m, 34H, $\mathrm{CH}_{2}$ dodecanoyl, myristyl), 1.48 (br. t, $2 \mathrm{H}, \mathrm{CH}_{2}$ dodecanoyl, myristyl) $1.56\left(\mathrm{~m}, 4 \mathrm{H}, \mathrm{CH}_{2}\right.$ dodecanoyl, myristyl), 2.12 (m, 2H, $\mathrm{CH}_{2}$ dodecanoyl, myristyl), 2.31 (m, $2 \mathrm{H}, \mathrm{CH}_{2}$ dodecanoyl, myristyl), 2.95 (br. s, $\left.2 \mathrm{H}, 2 \times \mathrm{OH}\right) 3.17\left(\mathrm{q}, 2 \mathrm{H}, \mathrm{CH}_{2}\right.$ dodecanoyl), 3.38 (s, 3H, OMe), $3.67\left(\mathrm{~m}, 1 \mathrm{H}, \mathrm{H}-5, \mathrm{~J}_{4,5}=9.7 \mathrm{~Hz}\right), 3.77\left(\mathrm{t}, 1 \mathrm{H}, \mathrm{H}-4, \mathrm{~J}_{3,4}=9.3\right.$, $\left.\mathrm{J}_{4,5}=9.5 \mathrm{~Hz}\right), 3.86\left(\mathrm{~d}, 2 \mathrm{H}, \mathrm{H}_{2}-6\right), 4.21\left(\mathrm{~m}, 1 \mathrm{H}, \mathrm{H}-2, \mathrm{~J}_{1,2}=3.6 \mathrm{~Hz}, \mathrm{~J}_{2, \mathrm{NH}}=9.4 \mathrm{~Hz}\right.$, $\mathrm{J}_{2,3}=9.4 \mathrm{~Hz}$ ), 4.69 (d, $\left.1 \mathrm{H}, \mathrm{H}-1, \mathrm{~J}_{1,2}=3.6 \mathrm{~Hz}\right), 4.78$ (br. s, $1 \mathrm{H}, \mathrm{NH}$ aminohexanoyl), 5.09 (br. s, $\left.3 \mathrm{H}, \mathrm{CH}_{2} \mathrm{Z}, \mathrm{H}-3\right), 5.83\left(\mathrm{~d}, 1 \mathrm{H}, \mathrm{NH}, \mathrm{J}_{2, \mathrm{NH}}=9.3 \mathrm{~Hz}\right), 7.27-7.36(\mathrm{~m}, 5 \mathrm{H}, \mathrm{CH}$-arom Z). ${ }^{13} \mathrm{C}\left\{{ }^{1} \mathrm{H}\right\}$ NMR $\left(\mathrm{CDCl}_{3}\right): \delta=14.17\left(\mathrm{CH}_{3}\right.$ myristyl $), 22.75-36.78\left(\mathrm{CH}_{2}\right.$ dodecanoyl, myristyl), $41.20\left(\mathrm{NCH}_{2}\right) 51.92(\mathrm{C}-2), 55.31(\mathrm{OMe}), 62.22(\mathrm{C}-6), 66.66\left(\mathrm{CH}_{2} \mathrm{Z}\right), 69.21$ (C-4), 71.45 (C-5), 73.82 (C-3), 98.53 (C-1), 126.81, 128.13, 128.72 (CH-arom Z), $136.72(\mathrm{Cq} \mathrm{Z}), 156.49(\mathrm{C}=\mathrm{O} \mathrm{Z}), 173.34,175.23(2 \times \mathrm{C}=\mathrm{O}$ amide, ester $)$.

Methyl 2-[(R)-3-(6-benzyloxycarbonylamino)hexanoyloxytetradecanoylamino]-2deoxy-3- $\boldsymbol{O}$-tetradecanoyl- $\boldsymbol{\alpha}$-D-glucopyranoside (27). To a cooled $\left(0^{\circ} \mathrm{C}\right)$ solution of $24(138 \mathrm{mg}, 0.151 \mathrm{mmol})$ in DCM $(1 \mathrm{~mL})$ was added TFA $(0.5 \mathrm{~mL})$. After stirring for $2 \mathrm{~h}$, TLC analysis indicated the complete conversion of starting material into a product with $R_{\mathrm{f}}=0.27$ (ethyl acetate/hexane, $2: 1, \mathrm{v} / \mathrm{v}$ ). The reaction mixture was concentrated and coevaporated with toluene $(2 \times 2 \mathrm{~mL})$. Silica gel column chromatography with hexane/ethyl acetate $(50: 50 \rightarrow 85: 15, \mathrm{v} / \mathrm{v})$ of the residue yielded the desired diol as a white solid $(115 \mathrm{mg} ; 87 \%)$. ${ }^{1} \mathrm{H}$ NMR $\left(\mathrm{CDCl}_{3}\right): \delta=0.88$ (t, 6H, $\mathrm{CH}_{3}$ acyloxyacyl, myristyl), $1.25-1.66\left(\mathrm{~m}, 40 \mathrm{H}, \mathrm{CH}_{2}\right.$ acyloxyacyl, myristyl), $1.51-1.66\left(\mathrm{~m}, 8 \mathrm{H}, \mathrm{CH}_{2}\right.$ acyloxyacyl, myristyl), 2.28-2.44 (m, $6 \mathrm{H}, \mathrm{CH}_{2}$, acyloxyacyl, myristyl), 2.68 (br. s, $1 \mathrm{H}$, OH-6), 3.18 (q, 2H, $\mathrm{CH}_{2}$ hexanoyl), 3.35 (s, 3H, OMe), 3.49 (br. s, 1H, OH-4), 3.64 (m, 1H, H-5), 3.74 (t, 1H, H-4), 3.84 (d, 2H, H2-6), 4.16 (m, 1H, H-2), 4.67 (d, 1H, H$\left.1, \mathrm{~J}_{1,2}=3.5 \mathrm{~Hz}\right), 5.02\left(\mathrm{~s}, 1 \mathrm{H}, \mathrm{NH}\right.$ aminohexanoyl), $5.09\left(\mathrm{~m}, 4 \mathrm{H}, \mathrm{CH}_{2} \mathrm{Z}, \mathrm{H}-3, \mathrm{CHO}\right.$ acyloxyacyl), $6.12(\mathrm{~d}, 1 \mathrm{H}, \mathrm{NH}), 7.28-7.35(\mathrm{~m}, 5 \mathrm{H}, \mathrm{CH}$-arom $\mathrm{Z}) .{ }^{13} \mathrm{C}\left\{{ }^{1} \mathrm{H}\right\}$ NMR $\left(\mathrm{CDCl}_{3}\right): \delta=14.09\left(\mathrm{CH}_{3}\right.$ myristyl), 22.69-41.31 $\left(\mathrm{CH}_{2}\right.$ acyloxyacyl, myristyl), 52.06 (C2), 55.20 (OMe), 62.08 (C-6), $66.63\left(\mathrm{CH}_{2} \mathrm{Z}\right), 69.14$ (C-4), 71.14 (CHO acyloxyacyl), 71.55 (C-5), 73.66 (C-3), 98.35 (C-1), 128.03, 128.06, 128.51 (CH-arom Z), 136.55 (Cq $\mathrm{Z}), 156.55(\mathrm{C}=\mathrm{O} \mathrm{Z}), 169.80,172.81,175.13(3 \times \mathrm{C}=\mathrm{O}$ amide, ester $)$.

Methyl 2-[(6-benzyloxycarbonylamino)hexanoylamino]-2,6-dideoxy-6- $O$-mesyl-3- $O$ tetradecanoyl- $\alpha$-D-glucopyranoside (28). To a stirred solution of 25 (301 mg, 0.463 $\mathrm{mmol})$ in dry pyridine $(10 \mathrm{~mL})$ was added mesyl chloride $(1.5$ equivalents, $60 \mu \mathrm{L})$. After $24 \mathrm{~h}$, methanol $(2 \mathrm{~mL})$ was added and the mixture was stirred for $0.5 \mathrm{~h}$, after which the mixture was concentrated. The residue was dissolved in DCM $(50 \mathrm{~mL})$ and washed with water $(1 \times 25 \mathrm{~mL})$. The organic layer was dried $\left(\mathrm{MgSO}_{4}\right)$ and concentrated under reduced pressure. The crude product was purified by silica gel column chromatography. Elution was performed with hexane/ethyl acetate $(70: 30 \rightarrow 20: 80, \mathrm{v} / \mathrm{v})$. $R_{\mathrm{f}}=0.43$ (hexane/ethyl acetate, 1:2, v/v). Yield $269 \mathrm{mg}(80 \%) .{ }^{1} \mathrm{H} \mathrm{NMR}\left(\mathrm{CDCl}_{3}\right)$ : $\delta=0.88\left(\mathrm{t}, 3 \mathrm{H}, \mathrm{CH}_{3}\right.$ myristyl), $1.25\left(\mathrm{~m}, 24 \mathrm{H}, \mathrm{CH}_{2}\right.$ hexanoyl, myristyl), 1.45-1.60 (m, $4 \mathrm{H}, \mathrm{CH}_{2}$ hexanoyl, myristyl), 2.13 (t, $2 \mathrm{H}, \mathrm{CH}_{2}$ hexanoyl, myristyl), $2.31\left(\mathrm{~m}, 2 \mathrm{H}, \mathrm{CH}_{2}\right.$ hexanoyl, myristyl), 3.05 (s, 3H, $\mathrm{CH}_{3} \mathrm{Ms}$ ), 3.15 (q, 2H, $\mathrm{NCH}_{2}$ hexanoyl), 3.39 (s, $3 \mathrm{H}$, OMe), 3.69 (m, 1H, H-4), 3.81 (br. d, 1H, OH-4), 3.86 (m, 1H, H-5), 4.23 (m, 1H, H2), 4.50 (q, 2H, $\left.\mathrm{H}_{2}-6\right), 4.70$ (d, $\left.1 \mathrm{H}, \mathrm{H}-1, \mathrm{~J}_{1,2}=3.6 \mathrm{~Hz}\right), 5.08$ (m, $4 \mathrm{H}, \mathrm{H}-3, \mathrm{CH}_{2} \mathrm{Z}, \mathrm{NH}$ aminohexanoyl), $5.99(\mathrm{~d}, 1 \mathrm{H}, \mathrm{NH}), 7.28-7.36(\mathrm{~m}, 5 \mathrm{H}, \mathrm{CH}$-arom $\mathrm{Z}) .{ }^{13} \mathrm{C}\left\{{ }^{1} \mathrm{H}\right\}$ NMR 
$\left(\mathrm{CDCl}_{3}\right): \delta=14.02\left(\mathrm{CH}_{3}\right.$ myristyl $), 22.58-36.16\left(\mathrm{CH}_{2}\right.$ hexanoyl, myristyl), $37.41\left(\mathrm{CH}_{3}\right.$ $\mathrm{Ms}), 40.70\left(\mathrm{CH}_{2} \mathrm{~N}\right), 51.60(\mathrm{C}-2), 55.40(\mathrm{OMe}), 66.45\left(\mathrm{CH}_{2} \mathrm{Z}\right), 68.14(\mathrm{C}-4), 68.59(\mathrm{C}-$ 6), 69.77 (C-5), 73.38 (C-3), 98.43 (C-1), 127.92-128.43 (CH-arom Z), 136.58 (Cq Z), $156.42(\mathrm{C}=\mathrm{O} \mathrm{Z}), 172.87,174.92(2 \times \mathrm{C}=\mathrm{O}$ amide, ester $)$.

Methyl 2-[(12-benzyloxycarbonylamino)dodecanoylamino]-2-deoxy-6- $O$-mesyl-3- $O$ tetradecanoyl- $\alpha$-D-glucopyranoside (29). Compound $29(1.175 \mathrm{~g}, 1.60 \mathrm{mmol})$ was prepared as described for compound 28. $R_{\mathrm{f}}=0.68$ (hexane/ethyl acetate, 1:2, v/v). Yield $1.01 \mathrm{~g}(78 \%) .{ }^{1} \mathrm{H}$ NMR $\left(\mathrm{CDCl}_{3}\right): \delta=0.88\left(\mathrm{t}, 3 \mathrm{H}, \mathrm{CH}_{3}\right.$ myristyl), $1.25\left(\mathrm{~m}, 34 \mathrm{H}, \mathrm{CH}_{2}\right.$ dodecanoyl, myristyl), 1.42-1.65 (m, 6H, $\mathrm{CH}_{2}$ dodecanoyl, myristyl), 2.12 (t, $2 \mathrm{H}, \mathrm{CH}_{2}$ dodecanoyl, myristyl), 2.32 (m, $2 \mathrm{H}, \mathrm{CH}_{2}$ dodecanoyl, myristyl), 3.07 (s, $3 \mathrm{H}, \mathrm{CH}_{3} \mathrm{Ms}$ ), 3.17 (q, 2H, $\mathrm{NCH}_{2}$ dodecanoyl), 3.31 (br. d, $\left.1 \mathrm{H}, \mathrm{OH}-4\right), 3.39$ (s, 3H, OMe), 3.70 (m, $\left.1 \mathrm{H}, \mathrm{H}-4, \mathrm{~J}_{3,4}=9.3 \mathrm{~Hz}, \mathrm{~J}_{4,5}=9.7 \mathrm{~Hz}\right), 3.86\left(\mathrm{~m}, 1 \mathrm{H}, \mathrm{H}-5, \mathrm{~J}_{4,5}=9.9 \mathrm{~Hz}, \mathrm{~J}_{5,6}=6.7 \mathrm{~Hz}\right.$, $\left.\mathrm{J}_{5,6^{\prime}}=3.3 \mathrm{~Hz}\right), 4.23\left(\mathrm{~m}, 1 \mathrm{H}, \mathrm{H}-2, \mathrm{~J}_{1,2} 3.6 \mathrm{~Hz}, \mathrm{~J}_{2,3}=9.4 \mathrm{~Hz}\right), 4.51\left(\mathrm{~d}, 2 \mathrm{H}, \mathrm{H}_{2}-6\right), 4.70(\mathrm{~d}$, $1 \mathrm{H}, \mathrm{H}-1, \mathrm{~J}_{1,2}=3.6 \mathrm{~Hz}$ ), 4.82 (br. s, $1 \mathrm{H}, \mathrm{NH}$ aminohexanoyl) 5.09 (dd $3 \mathrm{H}, \mathrm{H}-3, \mathrm{CH}_{2} \mathrm{Z}$,), $5.81\left(\mathrm{~d}, 1 \mathrm{H}, \mathrm{NH}, \mathrm{J}_{2, \mathrm{NH}}=8.9 \mathrm{~Hz}\right), 7.27-7.35(\mathrm{~m}, 5 \mathrm{H}, \mathrm{CH}$-arom $\mathrm{Z}) .{ }^{13} \mathrm{C}\left\{{ }^{1} \mathrm{H}\right\} \mathrm{NMR}$ $\left(\mathrm{CDCl}_{3}\right): \delta=14.12\left(\mathrm{CH}_{3}\right.$ myristyl), 22.69-36.67 $\left(\mathrm{CH}_{2}\right.$ dodecanoyl, myristyl), 37.59 $\left(\mathrm{CH}_{3} \mathrm{Ms}\right), 41.14\left(\mathrm{CH}_{2} \mathrm{~N}\right), 51.63(\mathrm{C}-2), 55.52(\mathrm{OMe}), 66.57\left(\mathrm{CH}_{2} \mathrm{Z}\right), 68.29(\mathrm{C}-4), 68.45$ (C-6), 69.87 (C-5), 73.44 (C-3), 98.60 (C-1), 128.06, 128.50 (CH-arom Z), $136.70(\mathrm{Cq}$ $\mathrm{Z}), 156.43(\mathrm{C}=\mathrm{O} \mathrm{Z}), 173.12,175.07(2 \times \mathrm{C}=\mathrm{O}$ amide, ester $)$.

Methyl 2-[(R)-3-(6-benzyloxycarbonylamino)hexanoyloxytetradecanoylamino]-2deoxy-3- $\boldsymbol{O}$-tetradecanoyl-6- $\boldsymbol{O}$-tosyl- $\alpha$-D-glucopyranoside (30). Compound 27 (115 $\mathrm{mg}, 0.131 \mathrm{mmol})$ was treated with tosyl chloride $(138 \mathrm{mg}, 0.724 \mathrm{mmol})$ in pyridine $(5$ $\mathrm{mL})$. After $96 \mathrm{~h}$, methanol $(2 \mathrm{~mL})$ was added and the mixture was concentrated. Further work-up as described for compound 28. The crude product was purified by silica gel column chromatography. Elution was performed with hexane/ethyl acetate $(60: 40 \rightarrow 35: 65, \mathrm{v} / \mathrm{v}) . R_{\mathrm{f}}=0.84$ (hexane/ethyl acetate, $\left.1: 2, \mathrm{v} / \mathrm{v}\right)$. Yield $107 \mathrm{mg}(79 \%) .{ }^{1} \mathrm{H}$ NMR $\left(\mathrm{CDCl}_{3}\right): \delta=0.88\left(\mathrm{t}, 6 \mathrm{H}, \mathrm{CH}_{3}\right.$ acyloxyacyl, myristyl), $1.25-1.49\left(\mathrm{~m}, 40 \mathrm{H}, \mathrm{CH}_{2}\right.$ acyloxyacyl, myristyl), $1.53\left(\mathrm{~m}, 8 \mathrm{H}, \mathrm{CH}_{2}\right.$ acyloxyacyl, myristyl), $2.34(\mathrm{~m}, 6 \mathrm{H}$, acyloxyacyl, myristyl), 2.44 (s, $\left.3 \mathrm{H}, \mathrm{CH}_{3} \mathrm{Ts}\right), 3.13(\mathrm{~s}, 1 \mathrm{H}, \mathrm{OH}-4), 3.18$ (q, $2 \mathrm{H}, \mathrm{CH}_{2}$ hexanoyl), 3.29 (s, 3H, OMe), $3.59(\mathrm{~m}, 1 \mathrm{H}, \mathrm{H}-4), 3.79(\mathrm{~m}, 1 \mathrm{H}, \mathrm{H}-5), 4.14(\mathrm{~m}, 1 \mathrm{H}, \mathrm{H}-$ 2), $4.30\left(\mathrm{~d}, 2 \mathrm{H}, \mathrm{H}_{2}-6\right), 4.59\left(\mathrm{~d}, 1 \mathrm{H}, \mathrm{H}-1, \mathrm{~J}_{1,2}=3.6 \mathrm{~Hz}\right), 4.94(\mathrm{t}, 1 \mathrm{H}, \mathrm{NH}$ aminohexanoyl), 5.04 (dd, 1H, H-3), 5.07 (s, 2H, $\left.\mathrm{CH}_{2} \mathrm{Z}\right) 5.09$ (m, 1H, CHO acyloxyacyl), 5.99 $(\mathrm{d}, 1 \mathrm{H}, \mathrm{NH}), 7.27-7.80\left(\mathrm{~m}, 9 \mathrm{H}, \mathrm{CH}\right.$-arom Ts/Z). ${ }^{13} \mathrm{C}\left\{{ }^{1} \mathrm{H}\right\}$ NMR $\left(\mathrm{CDCl}_{3}\right): \delta=14.11$ $\left(\mathrm{CH}_{3}\right.$ acyloxyacyl), $21.65\left(\mathrm{CH}_{3} \mathrm{Ts}\right), 22.69-41.30\left(\mathrm{CH}_{2}\right.$ acyloxyacyl, myristyl), 51.72 (C-2), 55.35 (OMe), $66.63\left(\mathrm{CH}_{2} \mathrm{Z}\right), 68.60$ (C-4), 68.80 (C-6), 69.84 (C-5), 71.13 (CHO acyloxyacyl), 73.43 (C-3), 98.22 (C-1), 127.76-129.84 (CH-arom Z), 133.01, 136.68, $144.98(\mathrm{Cq}$ Ts, $\mathrm{Z}), 156.52(\mathrm{C}=\mathrm{O} \mathrm{Z}), 169.62,172.76,175.07(3 \times \mathrm{C}=\mathrm{O}$ amide, ester $)$.

Methyl 6-azido-2-[(6-benzyloxycarbonylamino)hexanoylamino]-2,6-dideoxy-3-Otetradecanoyl- $\alpha$-D-glucopyranoside (31). To a solution of $\mathbf{2 8}(269 \mathrm{mg}, 0.369 \mathrm{mmol})$ in DMF $(10 \mathrm{~mL})$ was added sodium azide $(36 \mathrm{mg}, 0.55 \mathrm{mmol})$. After stirring for $4 \mathrm{~h}$ at $70^{\circ} \mathrm{C}$, TLC analysis indicated the complete conversion of starting material. The mixture was concentrated, diluted with DCM $(50 \mathrm{~mL})$ and washed with water $(20 \mathrm{~mL})$. The organic layer was dried $\left(\mathrm{MgSO}_{4}\right)$ and concentrated under reduced pressure. The crude 
product was purified by silica gel column chromatography. Elution was performed with hexane/ethyl acetate $(55: 45 \rightarrow 30: 70, \mathrm{v} / \mathrm{v}) . R_{\mathrm{f}}=0.76$ (hexane/ethyl acetate, $1: 2, \mathrm{v} / \mathrm{v}$ ). Yield $211 \mathrm{mg}(84 \%)$. ${ }^{1} \mathrm{H}$ NMR $\left(\mathrm{CDCl}_{3}\right): \delta=0.88\left(\mathrm{t}, 3 \mathrm{H}, \mathrm{CH}_{3}\right.$ myristyl), $1.25(\mathrm{~m}, 22 \mathrm{H}$, $\mathrm{CH}_{2}$ hexanoyl, myristyl), $1.54\left(\mathrm{~m}, 6 \mathrm{H}, \mathrm{CH}_{2}\right.$ hexanoyl, myristyl), $2.12\left(\mathrm{t}, 2 \mathrm{H}, \mathrm{CH}_{2}\right.$ hexanoyl, myristyl), 2.29 (m, $2 \mathrm{H}, \mathrm{CH}_{2}$ hexanoyl, myristyl), 3.17 (q, $2 \mathrm{H}, \mathrm{CH}_{2}$ hexanoyl), $3.41(\mathrm{~s}, 3 \mathrm{H}, \mathrm{OMe}), 3.46\left(\mathrm{dd}, 1 \mathrm{H}, \mathrm{H}-6, \mathrm{~J}_{5,6}=6.2 \mathrm{~Hz}, \mathrm{~J}_{6,6^{\prime}}=13.2 \mathrm{~Hz}\right), 3.57(\mathrm{dd}$, $\left.1 \mathrm{H}, \mathrm{H}-6^{\prime}, \mathrm{J}_{5,6^{\prime}}=2.5 \mathrm{~Hz}, \mathrm{~J}_{6,6^{\prime}}=13.2 \mathrm{~Hz}\right), 3.63\left(\mathrm{t}, 1 \mathrm{H}, \mathrm{H}-4, \mathrm{~J}_{3,4}=9.3 \mathrm{~Hz}, \mathrm{~J}_{4,5}=9.4 \mathrm{~Hz}\right)$, $3.79\left(\mathrm{~m}, 1 \mathrm{H}, \mathrm{H}-5, \mathrm{~J}_{4,5}=9.4 \mathrm{~Hz}, \mathrm{~J}_{5,6}=6.2 \mathrm{~Hz}, \mathrm{~J}_{5,6^{\prime}}=2.5 \mathrm{~Hz}\right), 4.25\left(\mathrm{~m}, 1 \mathrm{H}, \mathrm{H}-2, \mathrm{~J}_{1,2}=3.6\right.$ $\left.\mathrm{Hz}, \mathrm{J}_{2,3}=10.7 \mathrm{~Hz}, \mathrm{~J}_{2, \mathrm{NH}}=9.5 \mathrm{~Hz}\right), 4.70\left(\mathrm{~d}, 1 \mathrm{H}, \mathrm{H}-1 \mathrm{~J}_{1,2}=3.6 \mathrm{~Hz}\right), 4.92$ (br. s, $1 \mathrm{H}, \mathrm{NH}$ aminohexanoyl), 5.04 (dd, $\left.1 \mathrm{H}, \mathrm{H}-3, \mathrm{~J}_{2,3}=10.8 \mathrm{~Hz}, \mathrm{~J}_{3,4}=9.1 \mathrm{~Hz}\right), 5.08\left(\mathrm{~s}, 2 \mathrm{H}, \mathrm{CH}_{2} \mathrm{Z}\right.$ ), $5.87\left(\mathrm{~d}, 1 \mathrm{H}, \mathrm{NH}, \mathrm{J}_{2, \mathrm{NH}}=9.4 \mathrm{~Hz}\right), 7.27-7.35\left(\mathrm{~m}, 5 \mathrm{H}, \mathrm{CH}\right.$-arom Z). ${ }^{13} \mathrm{C}\left\{{ }^{1} \mathrm{H}\right\} \quad \mathrm{NMR}$ $\left(\mathrm{CDCl}_{3}\right): \delta=14.10\left(\mathrm{CH}_{3}\right.$ myristyl), 22.68-40.83 $\left(\mathrm{CH}_{2}\right.$ hexanoyl, myristyl), 51.42 (C-6), 51.64 (C-2), 55.40 (OMe), $66.63\left(\mathrm{CH}_{2} \mathrm{Z}\right), 69.76$ (C-4), 71.15 (C-5), 73.97 (C-3), 98.44 (C-1), 128.05, 128.09, 128.52 (CH-arom Z), $136.67(\mathrm{Cq} \mathrm{Z}), 156.49(\mathrm{C}=\mathrm{O} \mathrm{Z}), 172.73$, $175.28(2 \times \mathrm{C}=\mathrm{O}$ amide, ester $)$.

Methyl 6-azido-2-[(12-benzyloxycarbonylamino)dodecanoylamino]-2,6-dideoxy-3$\boldsymbol{O}$-tetradecanoyl- $\boldsymbol{\alpha}$-D-glucopyranoside (32). Compound $29(601 \mathrm{mg}, 0.738 \mathrm{mmol})$ was treated with sodium azide as described for the preparation of compound $\mathbf{3 1}$. $R_{\mathrm{f}}=0.60$ (hexane/ethyl acetate, 1:2, v/v). Yield $404 \mathrm{mg}(72 \%) .{ }^{1} \mathrm{H} \mathrm{NMR}\left(\mathrm{CDCl}_{3}\right)$ : $\delta=0.88\left(\mathrm{t}, 3 \mathrm{H}, \mathrm{CH}_{3}\right.$ myristyl), $1.25\left(\mathrm{~m}, 34 \mathrm{H}, \mathrm{CH}_{2}\right.$ dodecanoyl, myristyl), $1.51(\mathrm{~m}, 6 \mathrm{H}$, $\mathrm{CH}_{2}$ dodecanoyl, myristyl), 2.12 (m, $2 \mathrm{H}, \mathrm{CH}_{2}$ dodecanoyl, myristyl), 2.30 (m, $2 \mathrm{H}, \mathrm{CH}_{2}$ dodecanoyl, myristyl), 3.16 (q, 2H, $\mathrm{NCH}_{2}$ dodecanoyl), 3.42 (s, 3H, OMe), 3.46 (m, 2H, H-6, OH-4), 3.57 (dd, 1H, H-6'), 3.62 (m, 1H, H-4), 3.80 (m, 1H, H-5), 4.25 (m, $1 \mathrm{H}, \mathrm{H}-2), 4.71$ (d, 1H, H-1, J $\mathrm{J}_{1,2}=3.7 \mathrm{~Hz}$ ), 4.89 (br. s, 1H, NH dodecanoylamino), 5.05 (dd, $1 \mathrm{H}, \mathrm{H}-3$ ), 5.08 (br. s, $2 \mathrm{H}, \mathrm{CH}_{2} \mathrm{Z}$ ), 5.87 (d, $1 \mathrm{H}, \mathrm{NH} \mathrm{J} \mathrm{J}_{2, \mathrm{NH}}=9.4 \mathrm{~Hz}$ ), 7.28-7.35 (m, $5 \mathrm{H}, \mathrm{CH}$-arom Z). ${ }^{13} \mathrm{C}\left\{{ }^{1} \mathrm{H}\right\}$ NMR $\left(\mathrm{CDCl}_{3}\right): \delta=14.07\left(\mathrm{CH}_{3}\right), 22.64-41.08 \quad\left(\mathrm{CH}_{2}\right.$ dodecanoyl, myristyl), 51.37 (C-6), 51.57 (C-2), $55.32(\mathrm{OMe}), 66.51\left(\mathrm{CH}_{2} \mathrm{Z}\right), 69.62$ (C-4), 71.16 (C-5), 73.75 (C-3), 98.40 (C-1), 127.99, 128.44 (CH-arom Z), $136.64(\mathrm{Cq}$ $\mathrm{Z}), 156.42(\mathrm{C}=\mathrm{O} \mathrm{Z}), 173.06,175.21(2 \times \mathrm{C}=\mathrm{O}$ amide, ester $)$.

Methyl 6-azido-2-[(R)-3-(6-benzyloxycarbonylamino)hexanoyloxytetra-decanoylamino]-2,6-dideoxy-3- $O$-tetradecanoyl- $\alpha$-D-glucopyranoside (33). Compound 30 $(107 \mathrm{mg}, 0.103 \mathrm{mmol})$ was treated with sodium azide as described for the preparation of compound 31. $R_{\mathrm{f}}=0.26$ (hexane/ethyl acetate, $2: 1$, v/v). Yield $68 \mathrm{mg}(73 \%) .{ }^{1} \mathrm{H}$ NMR $\left(\mathrm{CDCl}_{3}\right): \delta=0.88\left(\mathrm{t}, 6 \mathrm{H}, \mathrm{CH}_{3}\right.$ acyloxyacyl, myristyl), $1.25\left(\mathrm{~m}, 40 \mathrm{H}, \mathrm{CH}_{2}\right.$ acyloxyacyl, myristyl), $1.56\left(\mathrm{~m}, 8 \mathrm{H}, \mathrm{CH}_{2}\right.$ acyloxyacyl, myristyl), $2.35\left(\mathrm{~m}, 6 \mathrm{H}, \mathrm{CH}_{2}\right.$ acyloxyacyl, myristyl), 3.05 (d, 1H, OH-4), 3.20 (t, 2H, hexanoyl), 3.39 (s, 3H, OMe), 3.45 (dd, 1H, H-6), 3.56 (dd, 1H, H-6'), 3.61 (t, 1H, H-4), 3.79 (m, 1H, H-5), 4.22 (m, $1 \mathrm{H}, \mathrm{H}-2), 4.70$ (d, 1H, H-1, J $\mathrm{J}_{1,2}=3.6 \mathrm{~Hz}$ ), 4.90 (br. s, $1 \mathrm{H}, \mathrm{NH}$ aminohexanoyl), 5.08 $\left(\mathrm{m}, 4 \mathrm{H}, \mathrm{CH}_{2} \mathrm{Z}, \mathrm{H}-3, \mathrm{CHO}\right.$ acyloxyacyl), $6.02(\mathrm{~d}, 1 \mathrm{H}, \mathrm{NH}), 7.27-7.35(\mathrm{~m}, 5 \mathrm{H}, \mathrm{CH}-$ arom Z). ${ }^{13} \mathrm{C}\left\{{ }^{1} \mathrm{H}\right\}$ NMR $\left(\mathrm{CDCl}_{3}\right): \delta=14.10\left(\mathrm{CH}_{3}\right.$ acyloxyacyl $), 22.71-41.31\left(\mathrm{CH}_{2}\right.$ acyloxyacyl, myristyl), 51.40 (C-6), 51.72 (C-2), 55.39 (OMe), $66.66\left(\mathrm{CH}_{2} \mathrm{Z}\right), 69.78$ (C-4), 69.89 (C-5), 71.15 (CHO acyloxyacyl), 73.75 (C-3), 98.28 (C-1), 128.06, 128.12, 128.54 (CH-arom Z), $136.62(\mathrm{Cq} \mathrm{Z}), 156.5(\mathrm{C}=\mathrm{O} \mathrm{Z}), 169.66,172.82,175.26$ $(3 \times \mathrm{C}=\mathrm{O}$ amide, ester $)$. 
Methyl 6-amino-2-[(6-benzyloxycarbonylamino)hexanoylamino]-2,6-dideoxy-3-Otetradecanoyl- $\alpha$-D-glucopyranoside (34). To a solution of $\mathbf{3 1}(491 \mathrm{mg}, 0.727 \mathrm{mmol})$ in THF (73 mL) was added triphenylphosphine $(286 \mathrm{mg}, 1.09 \mathrm{mmol})$ and water $(16 \mu \mathrm{L}$, $0.871 \mathrm{mmol})$. The mixture was refluxed for $3.5 \mathrm{~h}$, after which TLC analysis indicated the complete conversion of starting material into baseline material (hexane/ethyl acetate, 1:2, v/v). The reaction mixture was concentrated and the crude product was purified by silica gel column chromatography. Elution was performed with $\mathrm{MeOH} /$ DCM/TEA $(10: 89: 1 \rightarrow 14: 85: 1, \mathrm{v} / \mathrm{v} / \mathrm{v})$. Yield $497 \mathrm{mg}(100 \%)$. ${ }^{1} \mathrm{H}$ NMR $\left(\mathrm{CDCl}_{3}\right)$ : $\delta=0.88\left(\mathrm{t}, 3 \mathrm{H}, \mathrm{CH}_{3}\right.$ myristyl), $1.25\left(\mathrm{~m}, 22 \mathrm{H}, \mathrm{CH}_{2}\right.$ hexanoyl, myristyl), $1.54(\mathrm{~m}, 6 \mathrm{H}$, $\mathrm{CH}_{2}$ hexanoyl, myristyl), 2.12 (t, $2 \mathrm{H}, \mathrm{CH}_{2}$ hexanoyl, myristyl), $2.30\left(\mathrm{~m}, 2 \mathrm{H}, \mathrm{CH}_{2}\right.$ hexanoyl, myristyl), 2.77 (br. s, $3 \mathrm{H}, \mathrm{NH}_{2}-6, \mathrm{OH}-4$ ), 3.03 (br. s, 2H, $\mathrm{H}_{2}-6$ ), 3.17 (q, $2 \mathrm{H}$, $\mathrm{CH}_{2}$ hexanoyl), 3.36 (s, 3H, OMe), $3.60(\mathrm{~m}, 1 \mathrm{H}, \mathrm{H}-5), 3.64\left(\mathrm{t}, 1 \mathrm{H}, \mathrm{H}-4, \mathrm{~J}_{3,4}=8.6 \mathrm{~Hz}\right.$, $\left.\mathrm{J}_{4,5}=8.6 \mathrm{~Hz}\right), 4.18\left(\mathrm{~m}, 1 \mathrm{H}, \mathrm{H}-2, \mathrm{~J}_{1,2}=3.6 \mathrm{~Hz}, \mathrm{~J}_{2,3}=10.8 \mathrm{~Hz}, \mathrm{~J}_{2, \mathrm{NH}}=9.3 \mathrm{~Hz}\right), 4.65(\mathrm{~d}$, $1 \mathrm{H}, \mathrm{H}-1 \mathrm{~J}_{1,2}=3.6 \mathrm{~Hz}$ ), 4.95 (br. s, $1 \mathrm{H}, \mathrm{NH}$ aminohexanoyl), 5.08 (m, $3 \mathrm{H}, \mathrm{CH}_{2} \mathrm{Z}, \mathrm{H}-3$, $\left.\mathrm{J}_{2,3}=9.7 \mathrm{~Hz}, \mathrm{~J}_{3,4}=9.7 \mathrm{~Hz}\right), 5.87\left(\mathrm{~d}, 1 \mathrm{H}, \mathrm{NH}, \mathrm{J}_{2, \mathrm{NH}}=9.3 \mathrm{~Hz}\right), 7.28-7.36(\mathrm{~m}, 5 \mathrm{H}, \mathrm{CH}-$ arom Z). ${ }^{13} \mathrm{C}\left\{{ }^{1} \mathrm{H}\right\}$ NMR $\left(\mathrm{CDCl}_{3}\right): \delta=14.11\left(\mathrm{CH}_{3}\right.$ myristyl $), 22.69-40.86\left(\mathrm{CH}_{2}\right.$ hexanoyl, myristyl), 43.74 (C-6), 51.93 (C-2), 55.17 (OMe), $66.59\left(\mathrm{CH}_{2} \mathrm{Z}\right), 71.09$ (C-4), 71.34 (C-5), 73.71 (C-3), 98.43 (C-1), 128.06-128.60 (CH-arom Z), $136.74(\mathrm{Cq} \mathrm{Z})$, $156.45(\mathrm{C}=\mathrm{O} \mathrm{Z}), 172.69,174.99(2 \times \mathrm{C}=\mathrm{O}$ amide, ester $)$.

Methyl 6-amino-2-[(12-benzyloxycarbonylamino)dodecanoylamino]-2,6-dideoxy-3$\boldsymbol{O}$-tetradecanoyl- $\boldsymbol{\alpha}$-D-glucopyranoside (35). Compound 32 (914 $\mathrm{mg}, 1.20 \mathrm{mmol}$ ) was treated with triphenylphosphine as described for the preparation of compound 34. $R_{\mathrm{f}}=0.43(\mathrm{MeOH} / \mathrm{DCM}, 1: 9, \mathrm{v} / \mathrm{v})$. The crude product was purified by silica gel column chromatography. Elution was performed with MeOH/DCM/TEA (0:99.5:0.5 $\rightarrow$ 10:89.5:0.5, v/v/v). Yield $698 \mathrm{mg}(78 \%) .{ }^{1} \mathrm{H}$ NMR $\left(\mathrm{CDCl}_{3}\right): \delta=0.88\left(\mathrm{t}, 3 \mathrm{H}, \mathrm{CH}_{3}\right.$ myristyl), $1.25\left(\mathrm{~m}, 34 \mathrm{H}, \mathrm{CH}_{2}\right.$ hexanoyl, myristyl), $1.52\left(\mathrm{~m}, 6 \mathrm{H}, \mathrm{CH}_{2}\right.$ hexanoyl, myristyl), 2.09 ( $\mathrm{m}, 2 \mathrm{H}, \mathrm{CH}_{2}$ hexanoyl, myristyl), 2.31 (m, $2 \mathrm{H}, \mathrm{CH}_{2}$ hexanoyl, myristyl), 2.80 (br. s, $3 \mathrm{H}, \mathrm{NH}_{2}-6, \mathrm{OH}-4$ ), 3.03 (br. d, $2 \mathrm{H}, \mathrm{H}_{2}-6$ ), 3.17 (q, $2 \mathrm{H}, \mathrm{CH}_{2}$ hexanoyl), 3.37 (s, 3H, OMe), 3.55-3.67 (m, 2H, H-4, H-5), $4.19(\mathrm{~m}, 1 \mathrm{H}, \mathrm{H}-2), 4.66(\mathrm{~d}, 1 \mathrm{H}, \mathrm{H}-1$, $\mathrm{J}_{1,2}=3.6 \mathrm{~Hz}$ ), 4.83 (s, $1 \mathrm{H}, \mathrm{NH}$ aminohexanoyl), 5.09 (br. t, $3 \mathrm{H}, \mathrm{H}-3, \mathrm{CH}_{2} \mathrm{Z}$ ), 5.81 (d, $1 \mathrm{H}, \mathrm{NH}), 7.28-7.36\left(\mathrm{~m}, 5 \mathrm{H}, \mathrm{CH}\right.$-arom Z). ${ }^{13} \mathrm{C}\left\{{ }^{1} \mathrm{H}\right\}$ NMR $\left(\mathrm{CDCl}_{3}\right): \delta=14.12\left(\mathrm{CH}_{3}\right.$ myristyl), 22.70-41.14 ( $\mathrm{CH}_{2}$ hexanoyl, myristyl), 43.59 (C-6), 51.86 (C-2), 55.19 (OMe), $66.55\left(\mathrm{CH}_{2} \mathrm{Z}\right), 71.00(\mathrm{C}-4), 71.17(\mathrm{C}-5), 73.55$ (C-3), $98.45(\mathrm{C}-1), 128.05$, $128.50(\mathrm{CH}-\operatorname{arom~Z}), 136.74(\mathrm{Cq} \mathrm{Z}), 156.43(\mathrm{C}=\mathrm{O} \mathrm{Z}), 173.05,174.95(2 \times \mathrm{C}=\mathrm{O}$ amide, ester).

Methyl 6-amino-2-[(R)-3-(6-benzyloxycarbonylamino)hexanoyloxy-tetradecanoylamino-2,6-dideoxy-3- $O$-tetradecanoyl- $\alpha$-D-glucopyranoside (36). Compound 36 was prepared as described for compound $\mathbf{3 4}$. The crude product was purified by silica gel column chromatography. Elution was performed with MeOH/DCM/TEA (0:99:1 $\rightarrow$ 9:90:1, v/v/v). Yield $35 \mathrm{mg}(52 \%) .{ }^{1} \mathrm{H}$ NMR $\left(\mathrm{CDCl}_{3}\right): \delta=0.88\left(\mathrm{t}, 6 \mathrm{H}, \mathrm{CH}_{3}\right.$ acyloxyacyl, myristyl), $1.25\left(\mathrm{~m}, 40 \mathrm{H}, \mathrm{CH}_{2}\right.$ acyloxyacyl, myristyl), $1.55\left(\mathrm{~m}, 8 \mathrm{H}, \mathrm{CH}_{2}\right.$ acyloxyacyl, myristyl), 2.35 (m, 6H, $\mathrm{CH}_{2}$ acyloxyacyl, myristyl), 3.04-3.33 (m, 7H, OH-4, $\mathrm{NH}_{2}-6, \mathrm{H}_{2}-6, \mathrm{NCH}_{2}$ hexanoyl), 3.35 (s, 3H, OMe), 3.62-3.66 (m, 2H, H-4, H-5), 4.18 (m, 1H, H-2), 4.65 (d, 1H, H-1, J $\mathrm{J}_{1,2}=3.5 \mathrm{~Hz}$ ), 4.95 (br. s, $1 \mathrm{H}, \mathrm{NH}$ aminohexanoyl), $5.08\left(\mathrm{~m}, 4 \mathrm{H}, \mathrm{CH}_{2} \mathrm{Z}, \mathrm{H}-3, \mathrm{CHO}\right.$ acyloxyacyl), $6.00(\mathrm{~d}, 1 \mathrm{H}, \mathrm{NH}), 7.27-7.36(\mathrm{~m}, 5 \mathrm{H}$, 
$\mathrm{CH}$-arom Z). ${ }^{13} \mathrm{C}\left\{{ }^{1} \mathrm{H}\right\}$ NMR $\left(\mathrm{CDCl}_{3}\right): \delta=14.17\left(\mathrm{CH}_{3}\right.$ acyloxyacyl, myristyl), 22.74$41.34\left(\mathrm{CH}_{2}\right.$ acyloxyacyl, myristyl), $43.52(\mathrm{C}-6), 52.00(\mathrm{C}-2), 55.29(\mathrm{OMe}), 66.64\left(\mathrm{CH}_{2}\right.$ Z), 70.43 (C-4), 71.15 (CHO acyloxyacyl), 71.49 (C-5), 73.32 (C-3), 98.31 (C-1), 128.11, 128.56 (CH-arom Z), $136.74(\mathrm{Cq} \mathrm{Z}), 156.5(\mathrm{C}=\mathrm{O} \mathrm{Z}), 169.71,172.79,174.98$ $(3 \times \mathrm{C}=\mathrm{O}$ amide, ester $)$.

Compound 37. To a stirred mixture of $\mathbf{1 1}(30 \mathrm{mg}, 0.428 \mathrm{mmol})$, PyBOP (25 mg, $0.480 \mathrm{mmol})$ and DiPEA $(8.1 \mu \mathrm{L}, 0.480 \mathrm{mmol})$ in DCM $(3.6 \mathrm{~mL})$ a solution of amino sugar $34(28 \mathrm{mg}, 0.431 \mathrm{mmol})$ in DCM $(2.8 \mathrm{~mL})$ was added. After $1 \mathrm{~h}$, TLC analysis indicated the complete conversion of starting material into a compound with $R_{\mathrm{f}}=0.62$ $(\mathrm{MeOH} / \mathrm{DCM}, 7: 93$, v/v). The reaction mixture was diluted with DCM $(50 \mathrm{~mL})$ and washed with water $(1 \times 20 \mathrm{~mL})$. After drying over $\mathrm{MgSO}_{4}$, the organic layer was concentrated under reduced pressure. The crude product was purified by silica gel column chromatography. Elution was performed with hexane/ethyl acetate $(40: 60 \rightarrow$ 100:0, v/v). Yield $55 \mathrm{mg}(96 \%)$. ${ }^{1} \mathrm{H}$ NMR $\left(\mathrm{CDCl}_{3}\right): \delta=0.88\left(\mathrm{~m}, 6 \mathrm{H}, \mathrm{CH}_{3}\right.$ myristyl), 1.25 (br. s, $42 \mathrm{H}, \mathrm{CH}_{2}$ hexanoyl, myristyl), 1.52 (m, $8 \mathrm{H}, \mathrm{CH}_{2}$ hexanoyl, myristyl), $1.94\left(\mathrm{~m}, 3 \mathrm{H}, \mathrm{CH}_{2}\right.$ hexanoyl, $\left.\mathrm{OH}-4\right), 2.11\left(\mathrm{t}, 2 \mathrm{H}, \mathrm{CH}_{2}\right.$ hexanoyl), $2.27(\mathrm{~m}, 2 \mathrm{H}$, $\left.\mathrm{OCOCH}_{2}\right), 2.41\left(\mathrm{dd}, 1 \mathrm{H}, \mathrm{H}-1^{\prime} \mathrm{ax}, \mathrm{J}_{1^{\prime} \mathrm{ax}, 1^{\prime} \mathrm{eq}}=12.5 \mathrm{~Hz}, \mathrm{~J}_{1^{\prime} \mathrm{ax}, 2^{\prime}}=5.5 \mathrm{~Hz}\right), 2.90(\mathrm{~m}, 1 \mathrm{H}, \mathrm{H}-$ 6a), 3.04 (br. s, $1 \mathrm{H}, \mathrm{H}-5^{\prime}$ ), 3.10 (dd, $1 \mathrm{H}, \mathrm{H}-1^{\prime} \mathrm{eq}, \mathrm{J}_{1^{\prime} \mathrm{ax}, 1^{\prime} \mathrm{eq}}=12.5 \mathrm{~Hz}, \mathrm{~J}_{1^{\prime} \mathrm{eq}, 2^{\prime}}=3.0 \mathrm{~Hz}$ ), 3.17 (q, 2H, $\mathrm{NCH}_{2}$ hexanoyl), 3.29 (s, 3H, OMe), 3.39 (m, 3H, H-4, $\mathrm{NCH}_{2}$ acetyl), 3.52 (m, 1H, H-6'a), 3.55 (m, 1H, H-3'), 3.59 (m, 1H, H-5), 3.67 (t, 1H, H-4'), 3.83 (dd, 1H, H-6'b), 4.02 (m, 2H, H-2', H-6b), 4.12 (m, 1H, H-2), 4.45-4.67 (m, 7H, $3 \times \mathrm{CH}_{2}$ Bn, H-1), 4.82 (br. s, 1H, NHCOO), 5.09 (s, 2H, $\mathrm{CH}_{2} \mathrm{Z}$ ), 5.11 (t, 1H, H-3), 5.77 (d, 1H, NH-2), 6.35 (br. d, 1H, NH-2'), 7.25-7.35 (m, 20H, CH-arom Bn/Z), 7.82 (m, 1H, NH-6). ${ }^{13} \mathrm{C}\left\{{ }^{1} \mathrm{H}\right\} \quad$ NMR $\left(\mathrm{CDCl}_{3}\right): \delta=14.14\left(\mathrm{CH}_{3} 2 \times\right.$ myristyl $), 22.72-38.84\left(\mathrm{CH}_{2}\right.$ hexanoyl, myristyl), 39.85 (C-6), $40.91\left(\mathrm{NCH}_{2}\right.$ hexanoyl), $47.56\left(\mathrm{C}-2^{\prime}\right), 50.78\left(\mathrm{C}-1^{\prime}\right)$ $52.55(\mathrm{C}-2), 55.19(\mathrm{OMe}), 57.69\left(\mathrm{CH}_{2}\right.$ acetyl), $62.22\left(\mathrm{C}-5^{\prime}\right), 66.44\left(\mathrm{C}-6^{\prime}\right), 66.62\left(\mathrm{CH}_{2}\right.$ Z), 69.23 (C-4), 70.84 (C-5), 72.10 (C-3), 72.82, 73.35, $73.50\left(3 \times \mathrm{CH}_{2} \mathrm{Bn}\right), 76.93(\mathrm{C}-$ 3'), 77.28 (C-4'), 98.62 (C-1), 127.80-128.64 (CH-arom Bn, Z), 136.75, 137.66, 137.83, $137.86(4 \times \mathrm{Cq} \mathrm{Bn}, \mathrm{Z}), 156.75(\mathrm{C}=\mathrm{O} \mathrm{Z}), 172.59,172.76,173.18,174.65$ $\left(4 \times \mathrm{C}=\mathrm{O}\right.$ amide, ester). ES-MS; $m / z: 1332.9,[\mathrm{M}+\mathrm{H}]^{+}$; monoisotopic MW calculated for $\mathrm{C}_{78} \mathrm{H}_{117} \mathrm{~N}_{5} \mathrm{O}_{13}=1331.86$.

Compound 38. Compound $\mathbf{1 1}(22 \mathrm{mg}, 31.4 \mu \mathrm{mol})$ was coupled with compound $\mathbf{3 5}$ (24 mg, $32.7 \mu \mathrm{mol}$ ) as described for the preparation of compound 37. $R_{\mathrm{f}}=0.53(\mathrm{MeOH} /$ DCM, 5:95, v/v). Yield $42.8 \mathrm{mg}(96 \%)$. ${ }^{1} \mathrm{H}$ NMR $\left(\mathrm{CDCl}_{3}\right): \delta=0.88\left(\mathrm{~m}, 6 \mathrm{H}, \mathrm{CH}_{3}\right.$ myristyl), 1.25 (br. s, $52 \mathrm{H}, \mathrm{CH}_{2}$ dodecanoyl, myristyl), $1.46\left(\mathrm{~m}, 4 \mathrm{H}, \mathrm{CH}_{2}\right.$ dodecanoyl, myristyl), 1.55 (m, 8H, $\mathrm{CH}_{2}$ dodecanoyl, myristyl), $1.94(\mathrm{q}, 1 \mathrm{H}, \mathrm{OH}-4), 2.10(\mathrm{~m}, 2 \mathrm{H}$, $\mathrm{CH}_{2}$ dodecanoyl), $2.28\left(\mathrm{~m}, 2 \mathrm{H}, \mathrm{OCOCH}_{2}\right), 2.44\left(\mathrm{dd}, 1 \mathrm{H}, \mathrm{H}-1^{\prime} \mathrm{ax}, \mathrm{J}_{1^{\prime} \mathrm{ax}, 1^{\prime} \mathrm{eq}}=12.4 \mathrm{~Hz}\right.$, $\left.\mathrm{J}_{1^{\prime} \mathrm{ax}, 2^{\prime}}=5.2 \mathrm{~Hz}\right), 2.90\left(\mathrm{~m}, 1 \mathrm{H}, \mathrm{H}-6 \mathrm{a}, \mathrm{J}_{6 \mathrm{a}, 6 \mathrm{~b}}=12.4 \mathrm{~Hz}\right), 3.05$ (br. s, 1H, H-5'), 3.10 (dd, $\left.1 \mathrm{H}, \mathrm{H}^{\prime} \mathrm{1}^{\prime} \mathrm{eq}, \mathrm{J}_{1^{\prime} \mathrm{ax}, 1^{\prime} \mathrm{eq}}=12.5 \mathrm{~Hz}, \mathrm{~J}_{1^{\prime} \mathrm{eq}, 2^{\prime}}=3.1 \mathrm{~Hz}\right), 3.18\left(\mathrm{q}, 2 \mathrm{H}, \mathrm{NCH}_{2}\right.$ dodecanoyl), 3.29 (s, $3 \mathrm{H}, \mathrm{OMe}$ ), 3.38 (m, 3H, H-4, $\mathrm{NCH}_{2}$ acetyl), 3.52 (s, 1H, H-3'), 3.55 (m, 1H, H-6'a, $\mathrm{J}_{5^{\prime}, 6^{\prime} \mathrm{a}}=3.3 \mathrm{~Hz}, \mathrm{~J}_{6 \mathrm{a}^{\prime} \mathrm{b}^{\prime}}=10.3 \mathrm{~Hz}$ ), 3.60 (br. d, $\left.1 \mathrm{H}, \mathrm{H}-5, \mathrm{~J}_{4,5}=9.6 \mathrm{~Hz}\right), 3.68$ (t, $\left.1 \mathrm{H}, \mathrm{H}-4^{\prime}\right)$, $3.84\left(\mathrm{dd}, 1 \mathrm{H}, \mathrm{H}-6^{\prime} \mathrm{b}, \mathrm{J}_{5,6^{\prime} \mathrm{b}}=6.2 \mathrm{~Hz}, \mathrm{~J}_{6^{\prime} \mathrm{a}, 6^{\prime} \mathrm{b}}=10.2 \mathrm{~Hz}\right), 4.02(\mathrm{~m}, 1 \mathrm{H}, \mathrm{H}-6 \mathrm{~b}), 4.07(\mathrm{~m}, 1 \mathrm{H}$, $\left.\mathrm{H}-2^{\prime}\right), 4.11(\mathrm{~m}, 1 \mathrm{H}, \mathrm{H}-2), 4.45-4.71\left(\mathrm{~m}, 8 \mathrm{H}, \mathrm{H}-1, \mathrm{NHCOO}, 3 \times \mathrm{CH}_{2} \mathrm{Bn}, \mathrm{H}-1\right), 5.09(\mathrm{~s}$, $2 \mathrm{H}, \mathrm{CH}_{2} \mathrm{Z}$ ), 5.12 (t, $1 \mathrm{H}, \mathrm{H}-3, \mathrm{~J}=10.4 \mathrm{~Hz}$ ), 5.73 (d, 1H, NH-2), 6.36 (br. d, 1H, NH-2'), 7.22-7.35 (m, 20H, CH-arom Bn, Z), $7.85(\mathrm{~m}, 1 \mathrm{H}, \mathrm{NH}-6) .{ }^{13} \mathrm{C}\left\{{ }^{1} \mathrm{H}\right\}$ NMR $\left(\mathrm{CDCl}_{3}\right)$ : 
$\delta=14.20\left(\mathrm{CH}_{3}\right.$ dodecanoyl, myristyl $), 22.78-36.88\left(\mathrm{CH}_{2}\right.$ dodecanoyl, myristyl $), 39.85$ (C-6), $41.24\left(\mathrm{NCH}_{2}\right.$ dodecanoyl), 47 (C-2'), 50 (C-1') 52.56 (C-2), $55.25(\mathrm{OMe}), 57.78$ $\left(\mathrm{CH}_{2}\right.$ acetyl), $62\left(\mathrm{C}-5^{\prime}\right), 66.47\left(\mathrm{C}-6^{\prime}\right), 66.66\left(\mathrm{CH}_{2} \mathrm{Z}\right), 69.20(\mathrm{C}-4), 70.94(\mathrm{C}-5), 71.93$ (C-3), 72.86, 73.39, $73.52\left(3 \times \mathrm{CH}_{2} \mathrm{Bn}\right), 77.30\left(\mathrm{C}-3^{\prime}, \mathrm{C}-4^{\prime}\right), 98.69(\mathrm{C}-1), 127.86-$ $128.71(\mathrm{CH}-a r o m \mathrm{Bn} / \mathrm{Z}), 136.80,137.87(\mathrm{Cq} \mathrm{Bn}, \mathrm{Z}), 156(\mathrm{C}=\mathrm{O} \mathrm{Z}), 173.04,173.30$, 174.69, $\left(\mathrm{C}=\mathrm{O}\right.$ amide, ester). ES-MS; $\mathrm{m} / \mathrm{z}:$ 1416.85, $[\mathrm{M}+\mathrm{H}]^{+}$; monoisotopic MW calculated for $\mathrm{C}_{84} \mathrm{H}_{129}-\mathrm{N}_{5} \mathrm{O}_{13}=1415.96$.

Compound 39. Compound $11(10 \mathrm{mg}, 14.3 \mu \mathrm{mol})$ was coupled with compound $\mathbf{3 6}$ $(13.7 \mathrm{mg}, 15,7 \mu \mathrm{mol})$ as described for the preparation of compound 37. $R_{\mathrm{f}}=0.86$ $(\mathrm{MeOH} / \mathrm{DCM}, 5: 95, \mathrm{v} / \mathrm{v})$. Yield $11.4 \mathrm{mg}(51 \%) .{ }^{1} \mathrm{H} \mathrm{NMR}\left(\mathrm{CDCl}_{3}\right): \delta=0.88(\mathrm{t}, 9 \mathrm{H}$, $\mathrm{CH}_{3}$ acyloxyacyl, myristyl), $1.25\left(\mathrm{~m}, 60 \mathrm{H}, \mathrm{CH}_{2}\right.$ acyloxyacyl, myristyl), $1.52(\mathrm{~m}, 10 \mathrm{H}$, $\mathrm{CH}_{2}$ acyloxyacyl, myristyl), $1.94\left(\mathrm{~m}, 3 \mathrm{H}, \mathrm{OH}-4, \mathrm{CH}_{2}\right.$ myristyl), $2.30\left(\mathrm{~m}, 6 \mathrm{H}, \mathrm{NCH}_{2}\right.$ hexanoyl, $\mathrm{OCOCH}_{2}$ ), 2.42 (dd, 1H, H-1'ax), 2.88 (m, 1H, H-6a), 3.06 (br. s, 1H, H-5'), 3.11 (dd, 1H, H-1'eq), 3.18 (q, 2H, $\mathrm{NCH}_{2}$ hexanoyl), 3.27 (s, 3H, OMe), 3.35 (m, 1H,

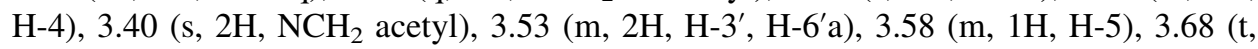
$\left.1 \mathrm{H}, \mathrm{H}-4^{\prime}\right), 3.83$ (dd, 1H, H-6'b), 4.03 (m, 2H, H-2', H-6b), 4.10 (m, 1H, H-2), 4.45$4.67\left(\mathrm{~m}, 7 \mathrm{H}, 3 \times \mathrm{CH}_{2} \mathrm{Bn}, \mathrm{H}-1\right), 4.85$ (br. s, $\left.1 \mathrm{H}, \mathrm{NHCOO}\right), 5.10$ (m, $4 \mathrm{H}, \mathrm{CH}_{2} \mathrm{Z}, \mathrm{H}-3$, CHO acyloxyacyl), 5.93 (d, 1H, NH-2), 6.32 (br. d, 1H, NH-2'), 7.25-7.35 (m, 20H, $\mathrm{CH}$-arom Bn, Z), $7.86(\mathrm{~m}, 1 \mathrm{H}, \mathrm{NH}-6) .{ }^{13} \mathrm{C}\left\{{ }^{1} \mathrm{H}\right\}$ NMR $\left(\mathrm{CDCl}_{3}\right): \delta=14.20\left(\mathrm{CH}_{3}\right.$ myristyl), 22.78-36.89 ( $\mathrm{CH}_{2}$ acyloxyacyl, myristyl), 39.85 (C-6), 40.94 (C-1'), 41.35 $\left(\mathrm{NCH}_{2}\right.$ hexanoyl), $47.47\left(\mathrm{C}-2^{\prime}\right), 52.61(\mathrm{C}-2), 55.19(\mathrm{OMe}), 57.81\left(\mathrm{CH}_{2}\right.$ acetyl), 62.16 $\left(\mathrm{C}-5^{\prime}\right), 66.48\left(\mathrm{C}^{\prime} 6^{\prime}\right), 66.67\left(\mathrm{CH}_{2} \mathrm{Z}\right), 69.20(\mathrm{C}-4), 70.87(\mathrm{C}-5), 71.16$ (CHO acyloxyacyl), 71.89 (C-3), 72.81, 73.40, 73.48 ( $\left.3 \times \mathrm{CH}_{2} \mathrm{Bn}\right), 76$ (C-3'), $77.30\left(\mathrm{C}-4^{\prime}\right), 98.48$ (C-1), 127.85-128.71 (CH-arom Bn, Z), 136.77, 137.64, 137.85 (Cq Bn, Z), 156.49 $(\mathrm{C}=\mathrm{O}$ Z $), 169.64,172.80,173.36,174.67(4 \times \mathrm{C}=\mathrm{O}$ amide, ester $)$. ES-MS; $m / z$ : 1559.00, $[\mathrm{M}+\mathrm{H}]^{+}$; monoisotopic $\mathrm{MW}$ calculated for $\mathrm{C}_{92} \mathrm{H}_{143} \mathrm{~N}_{5} \mathrm{O}_{15}=1558.05$.

Compound 40. Compound 12 ( $30 \mathrm{mg}, 0.334 \mathrm{mmol}$ ) was coupled with compound $\mathbf{3 4}$ (23 $\mathrm{mg}, 0.334 \mathrm{mmol}$ ) as described for the preparation of compound 37. $R_{\mathrm{f}}=0.48$ (hexane/ethyl acetate, $1: 4, \mathrm{v} / \mathrm{v})$. Yield $45 \mathrm{mg}(88 \%) .{ }^{1} \mathrm{H}$ NMR $\left(\mathrm{CDCl}_{3}\right): \delta 0.88=(\mathrm{dt}$, 9H, $\mathrm{CH}_{3}$ acyloxycyl, myristyl), 1.25 (br. s, $56 \mathrm{H}, \mathrm{CH}_{2}$ acyloxyacyl, hexanoyl, myristyl), $1.52\left(\mathrm{~m}, 10 \mathrm{H}, \mathrm{CH}_{2}\right.$ acyloxyacyl, hexanoyl, myristyl), $1.86(\mathrm{~s}, 1 \mathrm{H}, \mathrm{OH}-4), 2.11(\mathrm{t}, 2 \mathrm{H}$, $\mathrm{NCH}_{2}$ hexanoyl), 2.16-2.33 (m, $6 \mathrm{H}, \mathrm{CH}_{2}$ acyloxyacyl, hexanoyl, myristyl), 2.40 (dd, $\left.1 \mathrm{H}, \mathrm{H}-1^{\prime} \mathrm{ax}, \mathrm{J}_{1^{\prime} \mathrm{ax}, 1^{\prime} \text { eq }}=12.5 \mathrm{~Hz}, \mathrm{~J}_{1^{\prime} \mathrm{ax}, 2^{\prime}}=5.8 \mathrm{~Hz}\right), 2.96(\mathrm{~m}, 1 \mathrm{H}, \mathrm{H}-6 \mathrm{a}), 3.05$ (br. s, $1 \mathrm{H}, \mathrm{H}-$ $\left.5^{\prime}\right), 3.10\left(\mathrm{dd}, 1 \mathrm{H}, \mathrm{H}-1^{\prime}\right.$ eq, $\left.\mathrm{J}_{1^{\prime} \mathrm{ax}, 1^{\prime} \mathrm{eq}}=12.5 \mathrm{~Hz}, \mathrm{~J}_{1^{\prime} \mathrm{eq}, 2^{\prime}}=3.4 \mathrm{~Hz}\right), 3.17\left(\mathrm{q}, 2 \mathrm{H}, \mathrm{CH}_{2}\right.$ hexanoyl), 3.29 (s, 3H, OMe), $3.37(\mathrm{~m}, 1 \mathrm{H}, \mathrm{H}-4), 3.40$ (s, $2 \mathrm{H}, \mathrm{NCH}_{2}$ acetyl), $3.54(\mathrm{~m}, 2 \mathrm{H}$, H-6a', H-3'), 3.59 (m, 1H, H-5), 3.67 (t, 1H, H-4'), 3.83 (dd, 1H, H-6b'), 4.03 (m, 2H, H-2', H-6b), $4.12(\mathrm{~m}, 1 \mathrm{H}, \mathrm{H}-2), 4.44-4.67\left(\mathrm{~m}, 6 \mathrm{H}, 3 \times \mathrm{CH}_{2} \mathrm{Bn}\right), 4.50(\mathrm{~d}, 1 \mathrm{H}, \mathrm{H}-1)$, 4.81 (s, 1H, NHZ), 5.09 (m, 4H, $\mathrm{CH}_{2} \mathrm{Z}, \mathrm{H}-3, \mathrm{CHO}$ acyloxyacyl), 5.79 (d, 1H, NH-2), $6.55\left(\mathrm{~d}, 1 \mathrm{H}, \mathrm{NH}-2^{\prime}\right), 7.25-7.35(\mathrm{~m}, 20 \mathrm{H}, \mathrm{CH}-\operatorname{arom~Bn}, \mathrm{Z}), 7.87(\mathrm{~m}, 1 \mathrm{H}, \mathrm{NH}-6)$. ${ }^{13} \mathrm{C}\left\{{ }^{1} \mathrm{H}\right\}$ NMR $\left(\mathrm{CDCl}_{3}\right): \delta=14.16\left(\mathrm{CH}_{3}\right.$, dodecanoyl, myristyl $), 22.74-36.49\left(\mathrm{CH}_{2}\right.$ dodecanoyl, hexanoyl, myristyl), 39.78 (C-6), 40.91, 41.80, $41.92\left(\mathrm{CH}_{2}\right.$ myristyl, hexanoyl, dodecanoyl), 47.65 (C-2'), $50.93\left(\mathrm{C}^{\prime} \mathbf{1}^{\prime}\right), 52.56$ (C-2), 55.19 (OMe), 57.69 $\left(\mathrm{CH}_{2}\right.$ acetyl), $62.20\left(\mathrm{C}-5^{\prime}\right), 66.43\left(\mathrm{C}-6^{\prime}\right), 66.66\left(\mathrm{CH}_{2} \mathrm{Z}\right), 69.21(\mathrm{C}-4), 70.95(\mathrm{C}-5), 71.15$ (CHO acyloxyacyl), 72.12 (C-3), 72.83, $72.99,73.35\left(3 \times \mathrm{CH}_{2} \mathrm{Bn}\right), 76\left(\mathrm{C}-3^{\prime}\right), 77$ (C4'), 98.61 (C-1), 127.73-128.65 (CH-arom Bn, Z), 136.76, 137.80, 137.86, 137.89 
$(4 \times \mathrm{Cq} \mathrm{Bn}, \mathrm{Z}), 156.46(\mathrm{C}=\mathrm{O} \mathrm{Z}), 169.34,172.64,173.18,173.32,174.68(5 \times \mathrm{C}=\mathrm{O}$ amide, ester). ES-MS; $m / z$ : 1531.1, $[\mathrm{M}+\mathrm{H}]^{+}$; monoisotopic $\mathrm{MW}$ calculated for $\mathrm{C}_{90} \mathrm{H}_{139} \mathrm{~N}_{5} \mathrm{O}_{15}=1530.0$.

Compound 41. Compound $12(20 \mathrm{mg}, 22.2 \mu \mathrm{mol})$ was coupled with compound $\mathbf{3 5}$ (18 mg, $24.5 \mu \mathrm{mol})$ as described for the preparation of compound 37. $R_{\mathrm{f}}=0.62(\mathrm{MeOH} /$ DCM, 5:95, v/v). Yield $34.5 \mathrm{mg}(96 \%) .{ }^{1} \mathrm{H} \mathrm{NMR}\left(\mathrm{CDCl}_{3}\right): \delta=0.88\left(\mathrm{~m}, 9 \mathrm{H}, \mathrm{CH}_{3}\right.$ dodecanoyl, myristyl), 1.25 (m, 68H, $\mathrm{CH}_{2}$ acyloxyacyl, dodecanoyl, myristyl), 1.54 (m, $10 \mathrm{H}, \mathrm{CH}_{2}$ acyloxyacyl, dodecanoyl, myristyl), $2.10\left(\mathrm{~m}, 2 \mathrm{H}, \mathrm{NCH}_{2}\right.$ dodecanoyl), 2.23 (m, 6H, $\mathrm{CH}_{2}$ acyloxyacyl, dodecanoyl, myristyl), 2.43 (dd, 1H, H-1'ax, $\mathrm{J}_{1^{\prime} \text { ax, } 1^{\prime} \mathrm{eq}}=12.4$ $\left.\mathrm{Hz}, \mathrm{J}_{1^{\prime} \mathrm{ax}, 2^{\prime}}=5.1 \mathrm{~Hz}\right), 2.97\left(\mathrm{~m}, 1 \mathrm{H}, \mathrm{H}-6 \mathrm{a}, \mathrm{J}_{6 \mathrm{a}, 6 \mathrm{~b}}=12.6 \mathrm{~Hz}\right), 3.08$ (br. s, 1H, H-5'), 3.11 $\left(\mathrm{dd}, 1 \mathrm{H}, \mathrm{H}-1^{\prime}\right.$ eq, $\left.\mathrm{J}_{1^{\prime} \mathrm{ax}, 1^{\prime} \mathrm{eq}}=12.6 \mathrm{~Hz}, \mathrm{~J}_{1^{\prime} \mathrm{eq}, 2^{\prime}}=2.8 \mathrm{~Hz}\right), 3.18\left(\mathrm{q}, 2 \mathrm{H}, \mathrm{NCH}_{2}\right.$ acyl), $3.29(\mathrm{~s}$, $3 \mathrm{H}, \mathrm{OMe}$ ), 3.39 (m, 3H, H-4, $\mathrm{NCH}_{2}$ acetyl), 3.55 (m, 2H, H-6a', H-3'), 3.60 (m, 1H, H$\left.5, \mathrm{~J}_{4,5}=9.8 \mathrm{~Hz}\right), 3.67\left(\mathrm{t}, 1 \mathrm{H}, \mathrm{H}-4^{\prime}\right), 3.84\left(\mathrm{dd}, 1 \mathrm{H}, \mathrm{H}-6 \mathrm{~b}^{\prime}, \mathrm{J}_{5^{\prime}, 6 \mathrm{~b}^{\prime}}=6.3 \mathrm{~Hz}, \mathrm{~J}_{6 \mathrm{a}^{\prime}, 6 \mathrm{~b}^{\prime}}=10.5\right.$ $\mathrm{Hz}), 4.03\left(\mathrm{~m}, 1 \mathrm{H}, \mathrm{H}-6 \mathrm{~b}, \mathrm{~J}_{5,6 \mathrm{~b}}=4.2 \mathrm{~Hz}, \mathrm{~J}_{6 \mathrm{a}, 6 \mathrm{~b}}=12.6 \mathrm{~Hz}\right) 4.06\left(\mathrm{~m}, 1 \mathrm{H}, \mathrm{H}-2^{\prime}\right), 4.12(\mathrm{~m}$, $\left.1 \mathrm{H}, \mathrm{H}-2, \mathrm{~J}_{1,2}=3.5 \mathrm{~Hz}, \mathrm{~J}_{2,3}=9.8 \mathrm{~Hz}\right), 4.42-4.78\left(\mathrm{~m}, 8 \mathrm{H}, \mathrm{H}-1, \mathrm{NHZ}, 3 \times \mathrm{CH}_{2} \mathrm{Bn}\right), 5.08$ (m, 4H, $\mathrm{CH}_{2} \mathrm{Z}, \mathrm{H}-3$, CHO acyloxyacyl), 5.74 (d, 1H, NH-2, J $\left.{ }_{2, \mathrm{NH}}=9.1 \mathrm{~Hz}\right), 6.59$ (d, $\left.1 \mathrm{H}, \mathrm{NH}-2^{\prime}, \mathrm{J}_{2^{\prime} \mathrm{NH}}=6.3 \mathrm{~Hz}\right), 7.25-7.36(\mathrm{~m}, 20 \mathrm{H}, \mathrm{CH}$-arom Bn, Z), 7.87 (m, 1H, NH-6). ${ }^{13} \mathrm{C}\left\{{ }^{1} \mathrm{H}\right\}$ NMR $\left(\mathrm{CDCl}_{3}\right): \delta=14.20\left(\mathrm{CH}_{3} 3 \times\right.$ dodecanoyl, myristyl $), 22.78-36.87\left(\mathrm{CH}_{2}\right.$ acyloxyacyl, dodecanoyl, myristyl), 39.78 (C-6), 41.23, 41.79 ( $\mathrm{CH}_{2}$ acyloxyacyl, dodecanoyl, myristyl), 47.79 (C-2'), (50, C-1'), 52.53 (C-2), 55.21 (OMe), $57.69\left(\mathrm{CH}_{2}\right.$ acetyl), 62.20 (C-5'), $66.41\left(\mathrm{C}^{\prime} 6^{\prime}\right), 66.66\left(\mathrm{CH}_{2} \mathrm{Z}\right), 69.18$ (C-4), 71.03 (C-5), 71.13 (CHO acyloxyacyl), 71.95 (C-3), 72.83, 73.30, 73.35 (3 $\left.\times \mathrm{CH}_{2} \mathrm{Bn}\right), 77.09$ (C-3'), 77.31 (C-4'), 98.61 (C-1), 127.74-128.68 (CH-arom Bn, Z), 136.80, 137.88, (Cq Bn, Z), $156.46(\mathrm{C}=\mathrm{O} \mathrm{Z}), 169.31,173.02,173.18,173.25,174.66(4 \times \mathrm{C}=\mathrm{O}$ amide, ester $)$. ESMS; $m / z$ : 1615.00, $[\mathrm{M}+\mathrm{H}]^{+}$; monoisotopic MW calculated for $\mathrm{C}_{96} \mathrm{H}_{151} \mathrm{~N}_{5} \mathrm{O}_{15}=1614.12$.

Compound 1. To a solution of $37(10.4 \mathrm{mg}, 7.54 \mu \mathrm{mol})$ in DMF $(0.5 \mathrm{~mL}), \mathrm{Pd} / \mathrm{C}$ $(10 \%, 5 \mathrm{mg})$ was added. Hydrogen was passed through the stirred mixture for $46 \mathrm{~h}$. After filtration of the mixture over a PTFE filter, the filtrate was concentrated under reduced pressure. Yield $7 \mathrm{mg}$ quantitative. ${ }^{1} \mathrm{H}$ NMR (pyridine- $\left.\mathrm{d}_{5}\right): \delta=0.87(\mathrm{~m}, 6 \mathrm{H}$, $2 \times \mathrm{CH}_{3}$ acyl), $1.24\left(\mathrm{~m}, 43 \mathrm{H}, \mathrm{CH}_{2}\right.$ acyl), $1.39\left(\mathrm{~m}, 2 \mathrm{H}, \mathrm{CH}_{2}\right.$ acyl), $1.53\left(\mathrm{~m}, 2 \mathrm{H}, \mathrm{CH}_{2}\right.$ acyl), $1.65\left(\mathrm{~m}, 2 \mathrm{H}, \mathrm{CH}_{2}\right.$ acyl), $1.82\left(\mathrm{~m}, 4 \mathrm{H}, 2 \times \mathrm{CH}_{2}\right.$ acyl), $2.06\left(\mathrm{~m}, 2 \mathrm{H}, \mathrm{CH}_{2}\right.$ acyl), 2.18 (t, 1H, H-1'ax), 2.57-2.29 (m, 8H, $\mathrm{CH}_{2}$ acyl), 2.65 (m, 1H, H-5'), 3.05 (d, 1H, Hacetyl), 3.26 (t, 2H, CH $\mathrm{CH}_{2}$ acyl), 3.38 (dd, 1H, H-1'eq), 3.41 (s, 3H, OMe), 3.75 (m, 3H, H-acetyl, H-4', H-6a), 4.04 (dd, 1H, H-6b), 4.10 (dd, 1H, H-3'), 4.26 (t, 1H, H-4), 4.35 (t, 1H, H-6'a), 4.57 (m, 1H, H-5), 4.62 (m, 1H, H-2'), 4.86 (m, 1H, H-2), 4.97 (dd, 1H, H-6'b), 5.11 (d, 1H, H-1), 5.84 (dd, 1H, H-3), 8.65 (d, 1H, NH), 8.89 (d, 1H, NH'). ${ }^{13} \mathrm{C}\left\{{ }^{1} \mathrm{H}\right\}$ NMR (pyridine-d $\left.{ }_{5}\right): \delta=13.65\left(\mathrm{CH}_{3}\right.$ myristyl), 22.29-38.90 $\left(\mathrm{CH}_{2}\right.$ acyl), 40.62 $\left(\mathrm{C}-1^{\prime}\right), 50.75\left(\mathrm{C}-2^{\prime}\right), 51.76(\mathrm{C}-2), 54.69(\mathrm{C}-6), 55.16(\mathrm{OMe}), 57.14\left(\mathrm{CH}_{2}\right.$ acetyl), 59.73 $\left(\mathrm{C}-5^{\prime}\right), 69.02$ (C-5), 69.96 (C-4), $72.36\left(\mathrm{C}-6^{\prime}\right), 73.07$ (C-3), $73.56\left(\mathrm{C}-4^{\prime}\right), 75.78\left(\mathrm{C}-3^{\prime}\right)$, 99.12 (C-1), 166.63 ( $\mathrm{C}=\mathrm{O}$ ester), 172.71, 173.24, 173.31 ( $3 \times \mathrm{C}=\mathrm{O}$ amide). ES-MS; $m / z:$ 928.77, $[\mathrm{M}+\mathrm{H}]^{+}$; monoisotopic $\mathrm{MW}$ calculated for $\mathrm{C}_{49} \mathrm{H}_{93} \mathrm{~N}_{5} \mathrm{O}_{11}=927.69$.

Compound 2. Compound 38 (12.9 mg, $9.11 \mu \mathrm{mol})$ was treated as described for the preparation of compound 1. Yield $6.6 \mathrm{mg}(72 \%)$ of a white solid. ES-MS; $\mathrm{m} / \mathrm{z}$ : 1012.54, $[\mathrm{M}+\mathrm{H}]^{+}$; monoisotopic $\mathrm{MW}$ calculated for $\mathrm{C}_{55} \mathrm{H}_{105} \mathrm{~N}_{5} \mathrm{O}_{11}=1011.78$. 
Compound 3. Compound $39(1.9 \mathrm{mg}, 1.2 \mu \mathrm{mol})$ was treated as described for the preparation of compound 1 . Yield $0.7 \mathrm{mg}(54 \%)$ of a white solid. ES-MS; $\mathrm{m} / \mathrm{z}$ : 1154.98, $[\mathrm{M}+\mathrm{H}]^{+}$; monoisotopic $\mathrm{MW}$ calculated for $\mathrm{C}_{63} \mathrm{H}_{119} \mathrm{~N}_{5} \mathrm{O}_{13}=1153.88$.

Compound 4. Compound $40(6.7 \mathrm{mg}, 4.38 \mu \mathrm{mol})$ was treated as described for the preparation of compound 1. Yield $4.3 \mathrm{mg}(88 \%)$ of a white solid. ES-MS; $\mathrm{m} / \mathrm{z}: 1126.9$, $[\mathrm{M}+\mathrm{H}]^{+}$; monoisotopic MW calculated for $\mathrm{C}_{61} \mathrm{H}_{115} \mathrm{~N}_{5} \mathrm{O}_{13}=1125.85$.

Compound 5. Compound $41(8.2 \mathrm{mg}, 5.1 \mu \mathrm{mol})$ was treated as described for the preparation of compound 1 . Yield $4.0 \mathrm{mg}(65 \%)$ of a white solid. ES-MS; $m / z$ : 1211.18, $[\mathrm{M}+\mathrm{H}]^{+}$; monoisotopic MW calculated for $\mathrm{C}_{67} \mathrm{H}_{127} \mathrm{~N}_{5} \mathrm{O}_{13}=1209.94$.

\section{ACKNOWLEDGMENTS}

We thank S.H. van Krimpen for recording the NMR spectra and A.G. Hulst for performing electrospray MS analysis.

\section{REFERENCES}

1. Rietschel, E.Th.; Brade, L.; Lindner, B.; Zähringer, U. Biochemistry of Lipopolysaccharides in Bacterial Endotoxic Lipopolysaccharides. In Molecular Biochemistry and Cellular Biology; Morrison, D.C., Ryan, J.L., Eds.; CRC: Boca Raton, Florida, 1992; Vol. I, 4-41, Chapter 1.

2. Galanos, C.; Lüderitz, O.; Rietschel, E.Th.; Westphal, O.; Brade, H.; Brade, L.; Freudenberg, M.A.; Schade, F.U.; Imoto, M.; Yoshimura, S.; Kusumoto, S.; Shiba, T. Synthetic and natural Escherichia coli free lipid A express identical endotoxic activities. Eur. J. Biochem. 1985, 148, 1-5.

3. Chaby, R. Strategies for the control of LPS-mediated pathophysiological disorders. Drug Discovery Today 1999, 4, 209-221.

4. Opal, S.M.; Yu, R.L. Antiendotoxin strategies for the prevention and treatment of septic shock - new approaches and future directions. Drugs 1998, 55, 497508.

5. Wyckoff, T.J.O.; Raetz, C.R.H.; Jackman, J.E. Antibacterial and anti-inflammatory agents that target endotoxin. Trends Microbiol. 1998, 6, 154-159.

6. Landry, D.W.; Zhoa, K.; Yang, G.X.Q.; Glickman, M.; Georgiadis, T.M. Antibody-catalyzed degradation of cocaine. Science 1993, 259, 1899-1901.

7. Landry, D.W.; Yang, G.X.Q. Anti-cocaine catalytic antibodies - a novel approach to the problem of addiction. J. Addict Dis. 1997, 16, 1-17.

8. Mets, B.; Winger, G.; Cabrera, C.; Seo, S.; Jamdar, S.; Yang, G.; Zhao, K.; Briscoe, R.J.; Almonte, R.; Woods, J.H.; Landry, D.W. A catalytic antibody against cocaine prevents cocaine's reinforcing and toxic effects in rats. Proc. Natl. Acad. Sci. U.S.A. 1998, 95, 10176-10181.

9. Baird, T.J.; Deng, S.X.; Landry, D.W.; Winger, G.; Woods, J.H. Natural and artificial enzymes against cocaine. I. Monoclonal antibody 15A10 and the reinforcing effects of cocaine in rats. J. Pharmacol. Exp. Ther. 2000, 295, 1127-1134. 
10. Reymond, J.L.; Janda, K.D.; Lerner, R.A. Antibody catalysis of glycosidic bond hydrolysis. Angew. Chem., Int. Ed. Engl. 1991, 30, 1711-1713.

11. Suga, H.; Tanimoto, N.; Sinskey, A.J.; Masamune, S. Glycosidase antibodies induced to a half-chair transtition-state analog. J. Am. Chem. Soc. 1994, 116, 11197-11198.

12. Yu, J.H.; Hsieh, L.C.; Kochersperger, L.; Yonkovich, S.; Stephans, J.C.; Gallop, M.A.; Schultz, P.G. Progress toward an antibody glycosidase. Angew. Chem., Int. Ed. Engl. 1994, 33, 339-341.

13. Yu, J.; Choi, S.Y.; Lee, S.; Yoon, H.J.; Jeong, S.; Mun, H.; Park, H.; Schultz, P.G. Antibody-catalysed glycosyl transfer reactions from in vitro immunization. Chem. Commun. 1997, 1957-1958.

14. Yu, J.; Choi, S.Y.; Moon, K.D.; Chung, H.H.; Yuon, H.J.; Jeong, S.; Park, H.; Schultz, P.G. A glycosidase antibody elicited against a chair-like transition state analog by in vitro immunization. Proc. Natl. Acad. Sci. U.S.A. 1998, 95, 28802884.

15. Shabat, D.; Sinha, S.C.; Reymond, J.L.; Keinan, E. Catalytic antibodies as probes of evolution: modeling of a primordial glycosidase. Angew. Chem., Int. Ed. Engl. 1996, 35, 2628-2630.

16. Janda, K.D.; Lo, L.C.; Lo, C.H.L.; Sim, M.M.; Wang, R.; Wong, C.H.; Lerner, R.A. Chemical selection for catalysis in combinatorial antibody libraries. Science 1997, 275, 945-948.

17. Van den Berg, R.J.B.H.N.; Noort, D.; Milder-Enacache, E.S.; Van der Marel, G.A.; Van Boom, J.H.; Benschop, H.P. Approach toward a generic treatment of Gram-negative infections: synthesis of haptens for catalytic antibody mediated cleavage of the interglycosidic bond in lipid A. Eur. J. Org. Chem. 1999, 25932600.

18. Dong, W.L.; McCabe, K.W.; Bols, M.; Sierks, M.R. Catalytic antibodies for carbohydrate. Protein Eng. 1995, 8 (Suppl. S), 58.

19. Van den Broek, L.A.G.M.; Vermaas, D.J.; Heskamp, B.M.; Van Boeckel, C.A.A.; Tan, M.C.A.A.; Bolscher, J.G.M.; Ploegh, H.L.; Van Kemenade, F.J.; De Goede, R.E.Y.; Miedema, F. Chemical modification of azasugars, inhibitors of $N$ glycoprotein-processing glycosidases and of HIV-I infection - review and structure-activity-relationships. Recl. Trav. Chim. Pays-Bas. 1993, 112, 82-94.

20. Coste, J.; Le-Nguyen, D.; Castro, B. PYBOP - a new peptide coupling reagent devoid of toxic by-product. Tetrahedron Lett. 1990, 31, 205-208.

21. Kiso, M.; Tanaka, S.; Fujita, M.; Fujishima, Y.; Ogawa, Y.; Ishida, H.; Hasegawa, A. Synthesis of the optically active 4- $O$-phosphono-D-glycosamine derivatives related to the nonreducing sugar subunit of bacterial lipid A. Carbohydr. Res. 1987, 162, 127-140.

22. Foster, A.B.; Horton, D.; Stacey, M. Amino-sugar and related compounds. Part II. Observations on the acidic hydrolysis of derivatives of 2-amino-2-deoxy-Dglucose (D-glucosamine). J. Chem. Soc. 1957, 81-86.

23. Neises, B.; Steglich, W. Einfaches verfahren zur veresterung von carbonsäuren. Angew. Chem. 1978, 90, 556-557.

24. Leblanc, Y.; Fitzsimmons, B.J.; Adams, J.; Perez, F.; Rokach, J. The total synthesis of 12-HETE and 12,20-diHETE. J. Org. Chem. 1986, 51, 789-793.

25. Vaultier, M.; Knouzi, N.; Carrie, R. Reduction d'azides en amines primaires par 
une methode generale utilisant la reaction de staudinger. Tetrahedron Lett. 1983, $24,763-764$.

26. NMR spectrometry of compounds $\mathbf{2}-\mathbf{5}$ was performed with $\mathrm{CDCl}_{3}$, methanol- $\mathrm{d}_{4}$ and pyridine- $\mathrm{d}_{5}$ as solvents at ambient temperature.

Received November 5, 2001

Accepted January 28, 2002 